\title{
Cytoskeletal Movements and Substrate Interactions during Initiation of Neurite Outgrowth by Sympathetic Neurons in vitro
}

\author{
Carolyn L. Smith \\ Laboratory of Neural Control, NINDS, National Institutes of Health, Bethesda, Maryland 20892
}

The initial outgrowth of neurites from chick sympathetic neurons grown in vitro was investigated by time-lapse microscopy with laser-scanning and conventional light microscopes. Video-enhanced contrast, differential interference contrast optics (VECDIC) were used to monitor movements of neuronal cytoplasm, as well as the movements of small beads attached to the surface membrane, and interference reflection microscopy (IRM) was used to determine the concomitant pattern of attachment to the growth substrate (polyornithine or laminin). Related changes in the distributions of actin filaments, microtubules, and neurofilaments were determined by fluorescence labeling methods. Neurite formation on both substrates entailed invasion of the actin cores of filopodia by cytoplasm containing microtubules and neurofilaments. Small beads attached to the surface membrane surrounding the cytoplasm moved outward simultaneously with the cytoplasm. Cytoplasm invaded filopodia of neurons plated on laminin soon after attachment to the substrate or, for neurons generated in vitro, within as little as $\mathbf{3}$ min after cytokinesis. However, cytoplasm invaded filopodia of neurons grown on polyornithine only when they contacted a three-dimensional object such as another cell or a large, polyornithine-coated polystyrene bead. The observation that adhesion of filopodia to polyornithine-coated beads can initiate neurite formation is inconsistent with the commonly held view that neurite formation requires adhesion mediated by specific cell adhesion molecules. Simultaneous IRM and DIC imaging showed that cytoplasm invaded filopodia when only their tips were closely apposed to a substrate but not when they were closely apposed to a substrate along their entire lengths. These findings help to elucidate the mechanisms by which interactions between the cytoskeleton and the growth substrate initiate and produce the neuronal movements that lead to the formation of neurites.

IKey words: axon outgrowth, growth cone motility, growth cone guidance, neuronal polarity, microtubules, actin filaments]

\footnotetext{
Received May 12, 1993; revised July 6, 1993; accepted July 13, 1993.

I thank Dr. Judy Drazba for essential help with experiments involving laser scanning interference reflection microscopy. I am grateful to Drs. Thomas Reese, Gary Banker, Mark Terasaki, and Robert Burke for helpful discussions and critical reading of the manuscript. I also thank Ed Munro, Marcus Weiner, and Sharon Walter for excellent technical assistance.

Correspondence should be addressed to Carolyn L. Smith, Laboratory of Neural Control, NINDS, National Institutes of Health, Building 36, Room 2A29, Bethesda, MD 20892

Copyright (c) 1994 Society for Neuroscience $0270-6474 / 94 / 140384-15 \$ 05.00 / 0$
}

This article is concerned with the morphological changes, substrate interactions, and cytoskeletal interactions that lead to the initial outgrowth of neurites from neuronal cell bodies. Previous studies have shown that neurons grown in vitro extend filopodia and lamellipodia around their entire circumference prior to forming neurites (Collins, 1978a; Wessells et al., 1978; Luckenbill-Edds, 1979; Jacobs and Stevens, 1986; Cambray-Deakin et al., 1987; Dotti et al., 1988) and that some types neurons form filopodia before forming neurites in vivo (Ramon y Cajal, 1911; Nowakowski and Rakic, 1979; Jacobson and Huang, 1985; Lefcort and Bentley, 1989). At the later stages that are more commonly studied (Letourneau et al., 1991), neurons already have definitive neurites with growth cones at their tips. Although much is known about the morphological events and cytoskeletal mechanisms that lead to neurite elongation (Letourneau, 1982; Tosney and Wessells, 1983; Bray and Chapman, 1985; Goldberg and Burmcister, 1986; Alctta and Greene, 1988; Forscher and Smith, 1988; Mitchison and Kirschner, 1988; Smith, 1988; Lim ct al., 1989; Goldberg et al., 1991; Heidemann et al., 1991; Okabe and Hirokawa, 1991; Reinsch et al., 1991; Sheetz et al., 1992), relatively little is known about how neurons progress from the early stage, when they have filopodia, to the later stage, when they have neurites.

Filopodia at the leading edges of neuronal growth cones are known to participate in guiding neurite outgrowth. Filopodia adhere preferentially to certain substrates and, when they do so, they can initiate and direct the movements of cytoplasm that ultimately lead to elongation of the neurite (Nakai and Kawasaki, 1959; Bray and Chapman, 1985; Goldberg and Burmeister, 1986; O'Connor et al., 1990; Sabry et al., 1991). The observation that filopodia can guide growing neurites suggests that they could play an analogous role during the initial outgrowth of neurites. Interactions of neurons with the growth substrate clearly are important for the initiation of neurite outgrowth because neurons must adhere to a substrate in order to form neurites (Harrison, 1914), and they form neurites more rapidly when grown on certain substrates than on others (Letourneau, 1975; Collins, $1978 \mathrm{a}, \mathrm{b})$. However, it is not known whether interactions of neurons with the growth substrate can influence the orientation of initial neurite outgrowth.

The formation of neurites involves a rearrangement of the cytoskeleton. Filopodia and lamellipodia contain actin filaments, but neurites contain microtubules, and sometimes neurofilaments, in addition to actin. Although previous work has shown that microtubules are present in neurites at early times after their formation (Jacobs and Stevens, 1986; CambrayDeakin et al., 1987; Dotti and Banker, 1992), the exact time course by which microtubules and neurofilaments initially enter 
devcloping neurites has not becn described, nor is it clear how this process correlates with the overall changes in shape.

The present study examines neurite formation by single, freshly plated chick sympathetic neurons. Time-lapse recordings were made with video-enhanced contrast, differential interference contrast optics (VECDIC; Allen et al., 1981) in order to visualize movements of cytoplasm and overall changes in neuronal shape, and with laser scanning interference reflection microscopy (IRM; Curtis, 1964) in order to determine how closely different parts of the neuron were apposed to the growth substrate. After neurons were examined by video microscopy, they were fixed and stained with fluorescent markers for various components of the cytoskeleton. Neurons grown on substrates coated with laminin, a component of extracellular matrix that is known to promote neurite formation (Baron-Van Evercooren et al., 1982; Manthorpe et al., 1983), were compared with neurons grown on polyornithine, a positively charged poly-amino acid that promotes adhesion but not neurite formation (Letourneau, 1975). In cultures grown on polyornithine, neurite formation occurred when neurons contacted other cells or could be induced by adding polystyrene beads that had been coated with different adhesion molecules. The results provide a comprehensive picture of the substrate interactions and cytoskeletal responses that lead to the initiation of neurite outgrowth.

\section{Materials and Methods}

Cell culture. Sympathetic ganglia of chick embryos at day 7-9 of incubation were dissociated with trypsin and, after washing in medium containing horse serum, transferred to a defined medium (Marusich et al. 1986) consisting of Ham's F14 (GIBCO) with $20 \mathrm{ng} / \mathrm{ml} 7 \mathrm{~S}$ NGF (Sigma Chemical Corp., St. Louis, MO), $10 \mu \mathrm{g} / \mathrm{ml}$ avian transferrin (Cappel, Organon Teknika Corp., West Chester, PA), $5 \mu \mathrm{g} / \mathrm{ml}$ insulin (Collaborative Research, Bedford, MA), $5 \mathrm{ng} / \mathrm{ml}$ selenium (Collaborative Research), $1 \mathrm{mg} / \mathrm{ml}$ bovine serum albumin (Sigma, fiaction V), $100 \mathrm{U} / \mathrm{ml}$ penicillin, $100 \mathrm{U} / \mathrm{ml}$ streptomycin, and $250 \mathrm{ng} / \mathrm{ml}$ Fungizone (GIBCO Lab., Grand Island, NY). Cells were plated on acid-cleaned glass coverslips $(22 \times 22 \mathrm{~mm})$ coated with either polyornithine $(0.5$ $\mathrm{mg} / \mathrm{ml}$; Sigma P-8638) or polyornithine followed by laminin $(10 \mu \mathrm{g} / \mathrm{ml}$; Collaborative Research; Edgar et al., 1984). Coverslips photoetched with a grid pattern (Bellco, Vineland, NJ) usually were used to facilitate relocalization of individual cells. Cultures plated on laminin were examined immediately after plating but cultures plated on polyornithine were kept in a $\mathrm{CO}$, incubator for up $2 \mathrm{hr}$ prior to observation.

Video microscopy. For observation, a coverslip with attached cells was placcd on top of a chamber formed by attaching strips of silicone rubber (0.7 mm thick; North American Reiss, Bellemead, NJ) to a large glass coverslip $(22 \times 50 \mathrm{~mm}$, type 0 ; Gold Seal $)$ with silicone grease (Dow Corning). In most experiments, opposite sides of the chamber were left open to permit superfusion. The chamber was filled with a medium containing the same components as the plating medium but buffered with $10 \mathrm{mM}$ HEPES rather than bicarbonate and lacking phenol red. Cultures were superfused with fresh medium every 10-15 min. Alternatively, the chamber was filled with bicarbonate-buffered medium at $\mathrm{pH} 7.4$ and then tightly sealed with silicone grease. Judging from the color of the $\mathrm{pH}$ indicator, the medium in sealed chambers remained near $\mathrm{pH} 7.4$ for the duration of observation (up to $4 \mathrm{hr}$ ). The microscope stage was maintained at $\sim 36^{\circ} \mathrm{C}$ with an air stream incubator (Nikon).

Time-lapse recordings were made with video-enhanced contrast, differential interference contrast (VECDIC) microscopy (Allen et al., 1981) on an inverted microscope (Zeiss Axiovert) with a $100 \times(1.3 \mathrm{NA})$ Neofluar objective, a $1.4 \mathrm{NA}$ oil immersion condenser, and a $100 \mathrm{~W}$ halogen or $50 \mathrm{~W}$ mercury lamp. To minimize light-induced toxicity, the illumination was controlled by a shutter (Uniblitz; Vincent Associates, Rochester, NY), which was opened only during image acquisition. Cultures were observed with a Newvicon or silicon-intensified tube (SIT) video camera (Dage MTI, Michigan City, IN) and time-lapse images were collected at intervals of 4-60 sec. Images were averaged to reduce noise and processed to enhance contrast and eliminate shading with a digital image processor (Image 1, Universal Imaging, West Ches- ter, PA). Images were stored on an optical memory disk recorder (model 3031 or 2028, Panasonic, Secaucus, NJ). For reproduction, stored images were redigitized and edited with a Macintosh-based image proccssing system (Adobe PHOTOSHOP) and printed with a continuous-tone laser printer (Lasertechnics, Albuquerque, NM).

Simultaneous DIC and interference reflection microscopy (IRM) was performed with a Bio-Rad model 600 laser scanning system on an upright microscope (Zeiss) with a krypton/argon laser. Time-lapse images were collected in transmission and reflection modes using a $100 \mathrm{x}$ (1.3 NA) objective. To compare neurons grown on polyornithine and laminin, images were collected using the same gain and black level settings. The images were stored, edited, and printed as described above for images obtained by conventional microscopy.

Fluorescent labeling. After cells were examined by video microscopy, they were fixed and stained with labels for one or more components of the cytoskeleton. The fixation procedures differed depending on the label or combination of labels used. Cells were monitored with video microscopy during chemical fixation to assess the quality of preservation of structure.

For staining actin filaments, cells were fixed with $0.25 \%$ glutaraldehyde in $0.1 \mathrm{~m}$ sodium cacodylate bufer, $\mathrm{pH} 7.4$, and then permeabilized and stained in buffer containing $0.2 \%$ saponin and $0.33 \mu \mathrm{M}$ rhodamine phalloidin (Molecular Probes, Eugene, OR) as described by Bridgman and Dailey (1989). After fixation, cells were incubated in $1 \mathrm{mg} / \mathrm{ml} \mathrm{so-}$ dium borohydride to reduce autofluorescence in some experiments.

For staining microtubules, cells were quickly rinsed by perfusion of the observation chamber with phosphate-buffered saline (PBS) and then simultaneously fixed and permeabilized for $15 \mathrm{~min}$ in PIPES buffer $(80$ mM PIPFS) or PHFM buffer (60 mM PIPES and 25 mm HEPES) containing $3.7 \%$ paraformaldehyde, $0.25 \%$ glutaraldehyde, 5 mм EGTA, 1 $\mathrm{mm} \mathrm{MgCl}_{2}, 3 \%$ sucrose, and either $0.2 \%$ saponin or $1 \%$ Triton X-100 (modified from Schliwa and van Blerkom, 1981; Falconer et al., 1989). Rhodamine phalloidin $(0.33 \mu \mathrm{M})$ usually was added to the fixative to label actin filaments and it also seemed helpful in stabilizing filopodia, which otherwise sometimes broke during fixation. After fixation, cultures were removed from the observation chamber, washed with PBS, incubated for $20 \mathrm{~min}$ in blocking buffer (PBS with 5\% fetal bovine serum, $5 \%$ glycine, and $0.1 \%$ 'riton $X-100$ ), and then incubated overnight at $4^{\circ} \mathrm{C}$ in rat monoclonal antibodies against tyrosinated-tubulin $(\mathrm{YLl} / 2$; Accurate Chemical Corp., Westbury, NY) diluted 1:200 in blocking buffer or a mouse monoclonal antibody against acetylated-tubulin (611B-1; a gift of G. Piperno, Rockefeller Univ.) diluted 1:10. After washing, YLI/2-labeled cultures were incubated in biotinylated anti-rat IgG followed by fluorescein-avidin (Vector Lab., Burlingame, CA; both at $1: 1000$ in blocking buffer for $\mathrm{I} \mathrm{hr}$ at room temperature). Cultures labeled with 6-11 B- 1 were incubated for $1 \mathrm{hr}$ in blocking buffer with anti-mouse IgG conjugated to rhodamine (Cappel; 1:250) or Cy3 (Jackson Immunoresearch Lab., Westgrove, PA; 1:4000).

For double labeling with antibodies against tyrosinated-tubulin and acetylated-tubulin, cultures were fixed as described above and stained sequentially with $\mathrm{YL} 1 / 2$ and $6-11 \mathrm{~B}-1$. The secondary antibody for 6-11 B-1 (rhodamine- or (y3-conjugated anti-mouse IgG) was incubated with an equal volume of rat serum at $37^{\circ} \mathrm{C}$ for $30 \mathrm{~min}$ before dilution in blocking buffer to reduce cross-reaction with YL1/2.

For staining neurofilaments, coverslips were removed from the observation chamber and fixed by immersion in methanol at $-20^{\circ} \mathrm{C}$. After $5 \mathrm{~min}$ in methanol, the cultures were rinsed in PBS, blocked with PBS containing 5\% normal goat serum. Cells were incubated for $12 \mathrm{hr}$ in mouse monoclonal antibodies against the low-molecular-weight ( $68 \mathrm{kDa})$ neurofilament protein (Boehringer-Mannheim, Indianapolis, IN) at 1:50 in PBS plus goat serum, and for $1 \mathrm{hr}$ in rhodamine-conjugated antimouse IgG (Cappel) at 1:250 in PBS plus goat serum.

For fluorescence microscopy, coverslips were mounted in glycerol supplemented with para-phenylenediamine to reduce bleaching (Platt and Michael, 1983). Fluorescent images were collected with a Zeiss microscope and Bio-Rad laser scanning contocal imaging system. In some instances, a series of images collected at a spacing of 0.18 or 0.36 $\mu \mathrm{m}$ was superimposed to form a $\mathrm{z}$-series projection. Images were digitally processed to enhance contrast and printed with a Lasertechnics printer.

Experiments with coated beads. I arge polystyrene beads $(\sim 10 \mu \mathrm{m}$ in diameter) were obtained from Sigma while small carboxylate polystyrene beads $(0.5$ or $1.0 \mu \mathrm{m}$ in diameter) were obtained from Polysciences, Inc. (Warrington, PA). Polyornithine-coated beads were prepared by adding $200 \mu \mathrm{l}$ of large beads or $50 \mu \mathrm{l}$ of small beads to $1.0 \mathrm{ml}$ of 0.5 
Figure 1. Video images made with DIC optics showing a sympathetic neuron during initial attachment to a cov$\operatorname{erslip}(A)$ and $1 \mathrm{hr}$ after plating $(B)$. When freshly plated, the neuron had several filopodia (arrowheads). One hour later, it had long neurites (arrows) with growth cones at their tips. The coverslip was coated with laminin. Scale bar, $10 \mu \mathrm{m}$.

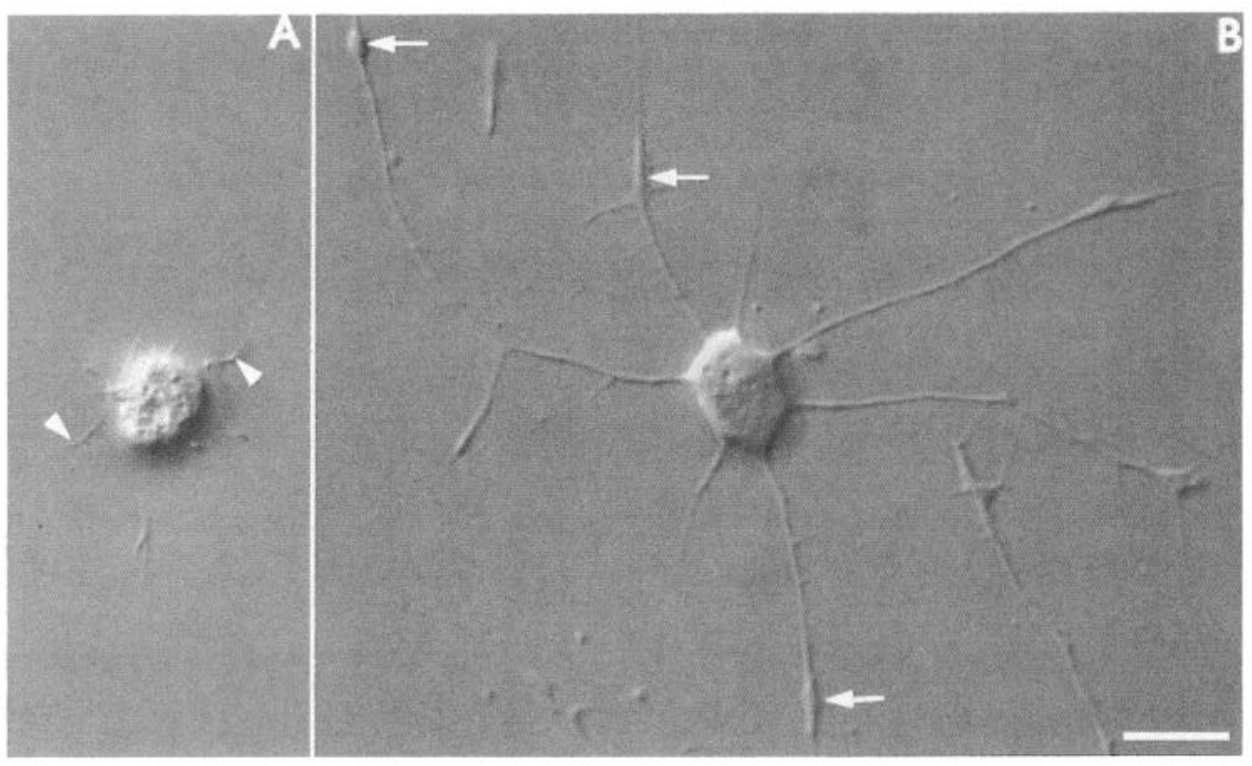

$\mathrm{mg} / \mathrm{ml}$ polyornithine in $62 \mathrm{~mm}$ borate buffer at $\mathrm{pH} 8.3$ (modified from Collins, 1978a). The beads were kept for $12 \mathrm{hr}$ at $37^{\circ} \mathrm{C}$, washed three times in sterile water, and stored at $4^{\circ} \mathrm{C}$ until used. Laminin-coated beads were prepared by incubating polyornithine-coated beads in $1 \mathrm{ml}$ of $10 \mu \mathrm{g} / \mathrm{ml}$ laminin in PBS for $12 \mathrm{hr}$ at $37^{\circ} \mathrm{C}$. For DIC microscopy on an inverted microscope, beads were resuspended in culture medium and then superfused onto cultures during observation. For laser scanning VECDIC and IRM on an upright microscope, beads were dried onto the coverslip before the cells were plated.

\section{Results}

Sympathetic neurons examined immediately after dissociation had round cell bodies and multiple filopodia (Fig. 1 $A$ ). A few neurons also had one or two thicker processes, but these usually retracted within the first $15 \mathrm{~min}$ after plating. Neurons began to form neurites within a few minutes after they attached to the substrate and, within $1 \mathrm{hr}$, some neurites had extended $50 \mu \mathrm{m}$ or more (Fig. 1B). At the second stage, the neurons morphologically resembled neurons described in previous studies (Bray, 1973). Their neurites contained both microtubules and neurofilaments and probably were axons rather than dendrites, since sympathetic neurons only form axons when grown in defined medium (Bruckenstein and Higgins, 1988). The present study focuses on the initial steps in the transition from the first stage to the second.

\section{Neurons grown on laminin begin to form neurites spontaneously}

In initial experiments, neurons were grown on laminin because laminin is known to promote neurite outgrowth. Cultures were prepared from embryonic sympathetic ganglia that contained postmitotic neurons as well as neuroblasts, which retain the ability to divide in vitro (Rohrer and Thoenen, 1987). Both neurons (Fig. 2) and neuroblasts (not illustrated) rapidly formed long neurites. However, neuroblasts subsequently retracted their neurites and divided. Newly postmitotic neurons had round cell bodies and multiple filopodia. They began to form neurites as soon as $3 \mathrm{~min}$ after division.

Neurite formation by all cells involved thickening of filopodia by invasion of cytoplasm from the perinuclear region (Fig. 2). Cytoplasm typically began to invade several filopodia of a given neuron at approximately the same time. In some instances, the cytoplasmic protrusions were initially several micrometers wide and engulfed several adjacent filopodia. These wide cytoplasmic protrusions subsequently narrowed and rounded up, thereby acquiring the cylindrical shape typical of neurites. Cytoplasm only invaded filopodia that contacted the substrate. However, cytoplasm did not invade every filopodium that contacted the substrate and it was not clear why it invaded some filopodia but not others. Many neurons also formed veil-like lamellipodia prior to or during neurite formation, but only lamellipodia that lay along the sides of filopodia were invaded by cytoplasm and incorporated into developing neurites.

Since the movements of cytoplasm that resulted in the formation of neurites were directed along paths defined by filopodia, the initial branching patterns of neurons reflected the distributions of their filopodia. In some instances, a pair of cells generated by division of a neuroblast formed branching patterns that were roughly mirror symmetrical, as was found in studies of neuroblastoma cells (Soloman, 1979) but, frequently, the branching patterns were not symmetrical. During subsequent development, the branching patterns of neurons were modified by growth, retraction, and fusion of branches as well as by translocation of the cell body, as has been described previously (Bray, 1973, 1979; Jacobs and Stevens, 1987).

\section{Neurons growing on polyornithine only form neurites after they contact another cell}

Neurons plated on polyornithine formed a lamella around their entire circumference. Cytoplasm containing organelles was present in the perinuclear region, which remained rounded, but not in the lamella. Isolated neurons did not form neurites. However, if a neuron was adjacent to another cell and one of its filopodia contacted the cell, then cytoplasm from the perinuclear region invaded the filopodium, converting it into a neurite (Fig. 3). The interval between contact and the initial movement of cytoplasm was as short as $1 \mathrm{~min} 10 \mathrm{sec}$ (average interval $=9 \mathrm{~min}$ $52 \mathrm{sec}$ for 31 neurons). Neurons that contacted other neurons almost invariably formed neurites, although not all neurons that contacted non-neuronal cells did. Since neurons grown on polyornithine formed neurites rapidly and reliably when they con- 


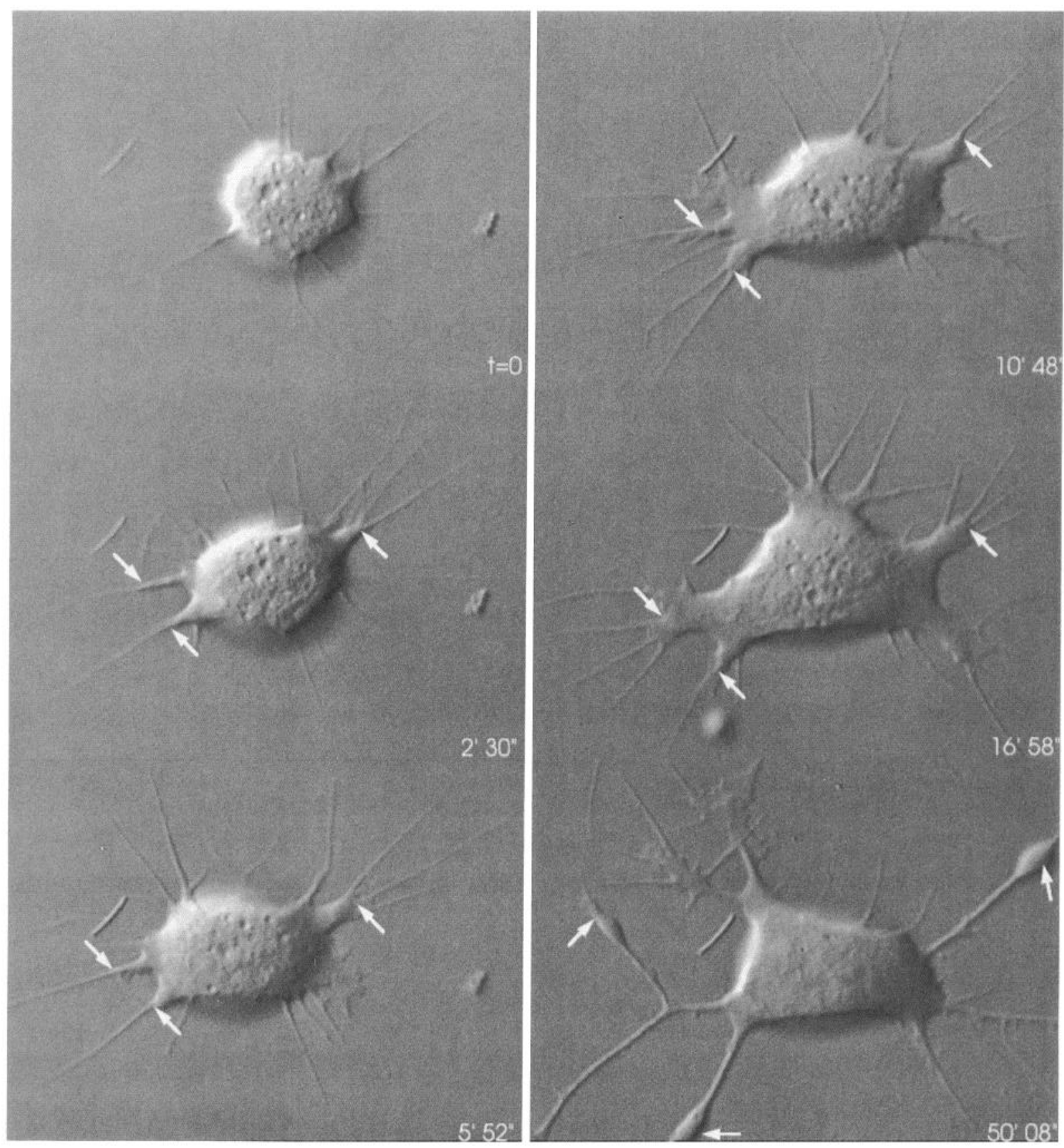

Figure 2. Steps in the initiation of neurite outgrowth on laminin. The sequence begins $5 \mathrm{~min}$ after plating. Elapsed time is given in minutes and seconds. At 2'30" cytoplasm had begun to invade several filopodia (arrows). As each cytoplasmic protrusion advanced, it progressively engulfed additional filopodia. At $10^{\prime} 48^{\prime \prime}$ and $16^{\prime} 58^{\prime \prime}$, the protrusions were broad and flat, but by $50^{\prime} 08^{\prime \prime}$ they had rounded up and were narrow except at their tips (arrows).

tacted other neurons, this system provided a useful model for studying the initiation of neurite outgrowth. Also, neurons grown on polyornithine had flatter margins than neurons grown on laminin, making cytoplasmic movements easier to resolve.

Neurite formation typically was initiated by contact of a filopodium with a filopodium of another neuron (Fig. 3). Filopodia seemed to adhere strongly to each other because they rarely separated. Each filopodia then elongated, growing along the other until it reached the cell body of the other neuron. The filopodia straightened as they grew, suggesting that they attached to each other more strongly than to the substrate and that they were under tension. Cytoplasm from the perinuclear region began to invade the portion of the lamella surrounding the base of each filopodium just as the filopodium straightened (Fig. 3) or shortly thereafter. Portions of the lamella that had been invaded by cytoplasm were clearly distinct from those that had not been invaded because they were thicker, contained organelles, and had different cytoskeletal compositions (see below).

The path of the cytoplasm was aligned with the long axis of the filopodium and, if the angular orientation of the filopodium changed, then the path of the cytoplasm changed correspondingly. It appeared as though the cytoplasm was pulled outward by a mechanism that involved shortening of the filopodium. The nucleus and perinuclear cytoplasm shifted toward the fil- 


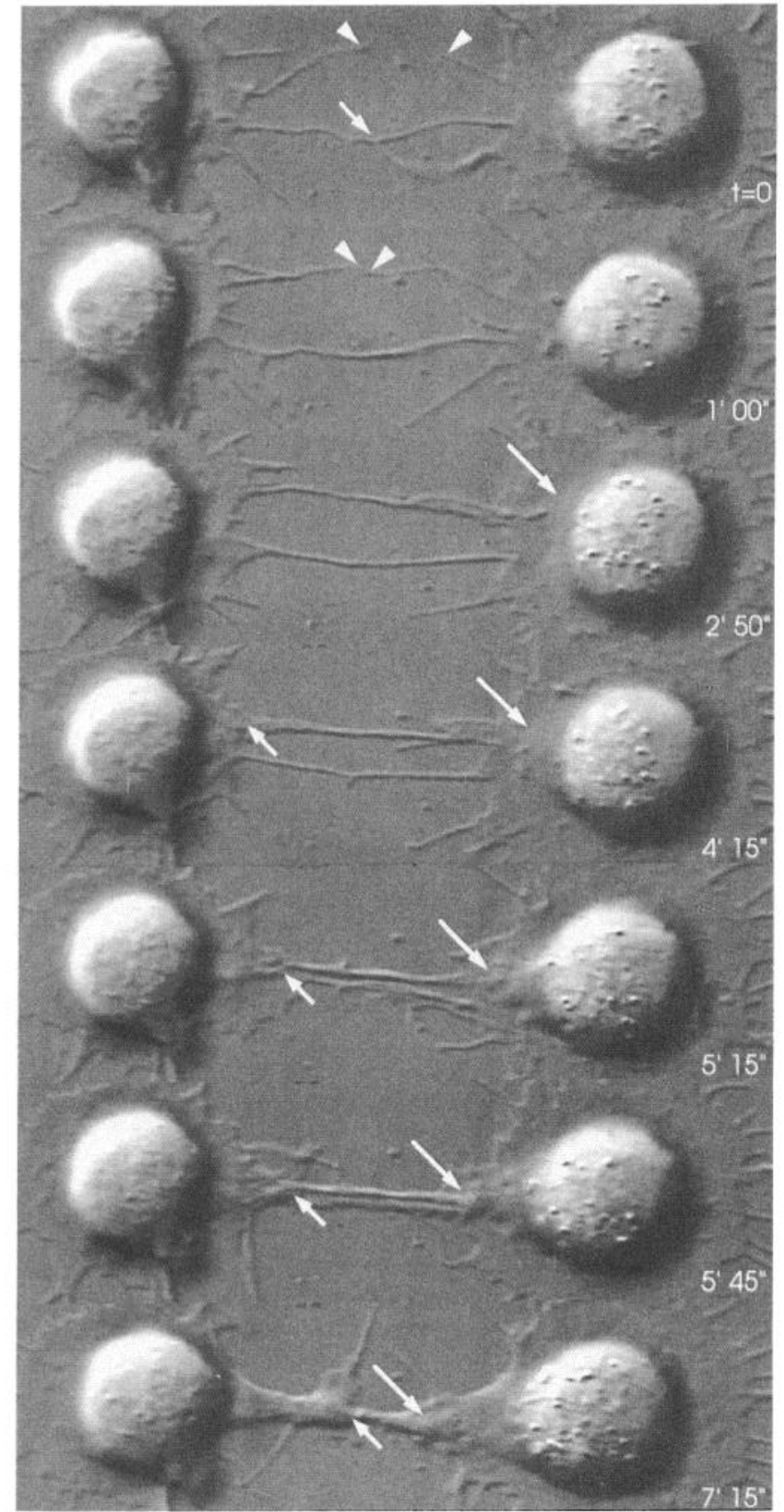

Figure 3. Neurite formation induced by contact of a filopodium with another cell. At the beginning of the sequence, filopodia of two adjacent neurons growing on polyornithine had just come into contact (arrow). A second pair of filopodia (arrowheads) came into contact at $I^{\prime} 00^{\prime \prime}$. The cell bodies of the neurons were surrounded by thin lamellae. At $2^{\prime} 50^{\prime \prime}$, the two pairs of filopodia had begun to straighten and cytoplasm from the perinuclear region of the neuron on the right had begun to invade the lamella (long arrow). In subsequent images, the long arrows follow the leading edge of the cytoplasm as it invades a filopodium. Cytoplasm began to invade a filopodium of the neuron on the left at 4'15" (short arrows). Although each neuron initially had two filopodia that contacted the adjacent neuron, the two filopodia moved together and, by $7^{\prime} 15^{\prime \prime}$, they appeared to have fused. Note that the cell bodies of the neurons moved toward each other between $2^{\prime} 50^{\prime \prime}$ and $7^{\prime} 15^{\prime \prime}$.

opodium as it filled with cytoplasm (see Figs. 3, 8), suggesting that they were pulled by the same mechanism. When two or more filopodia of a given neuron contacted the same cell, these filopodia usually were drawn together as they straightened and

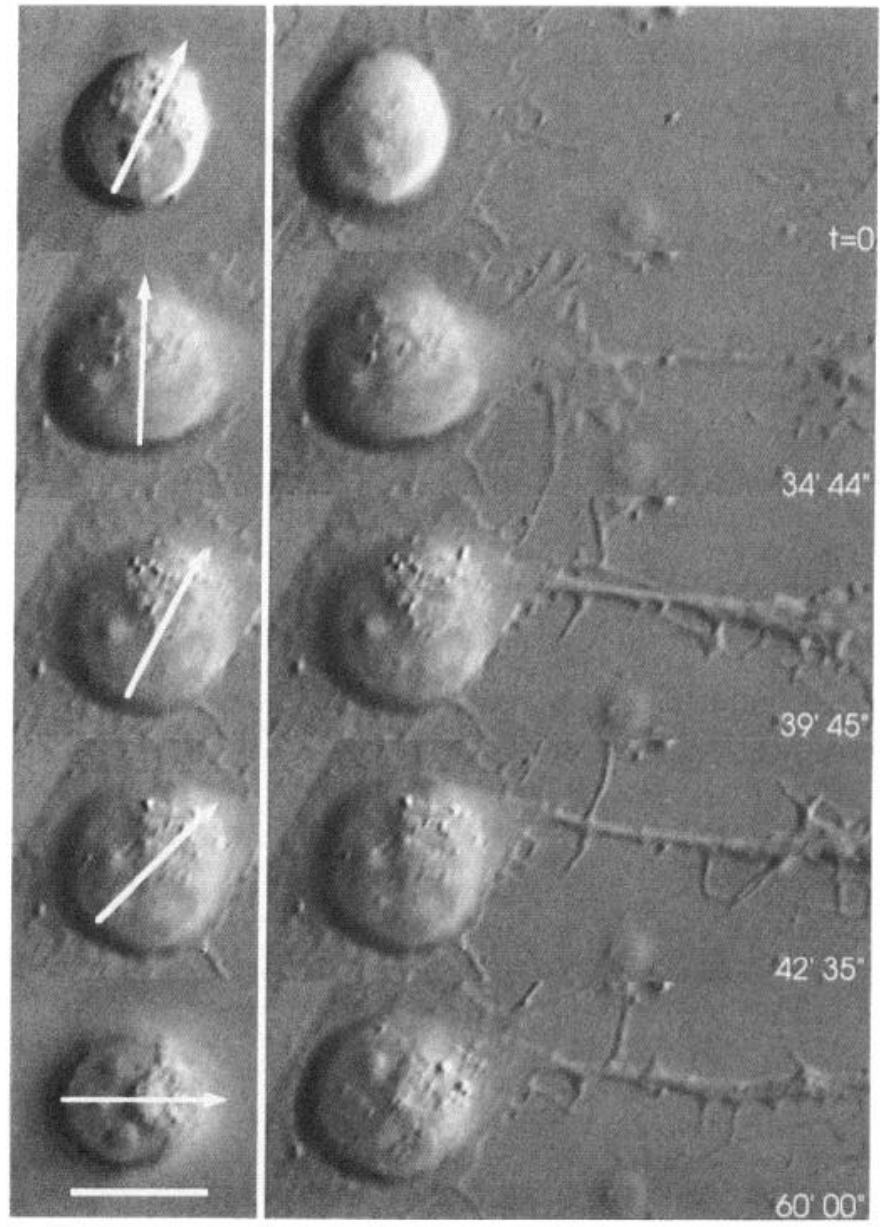

Figure 4. Rotation of the cell body in relation to neurite formation on polyornithine. The cell axis is defined in the left panel by arrows that bisect the nucleus (in focus at $t=0$ and $60^{\prime} 00^{\prime \prime}$ ) and main mass of cytoplasm. The cell axis rotated clockwise $25^{\circ}$ between the beginning of the sequence $(t=0)$ and the second image $\left(34^{\prime} 44^{\prime \prime}\right)$, when cytoplasm had begun to invade a filopodium, but then began to rotate counterclockwise. By $60^{\prime} 00^{\prime \prime}$, the cell axis had rotated $75^{\circ}$ counterclockwise and was aligned with the developing neurite. Scale bar, $10 \mu \mathrm{m}$.

eventually appeared to fuse (Fig. 3) . However, if they contacted different neurons, they remained separate and, often, each was invaded by cytoplasm.

Cytoplasm moved anterogradely in filopodia at rates of up to $9.4 \mu \mathrm{m} / \mathrm{min}$. However, periods of advance often were interrupted by periods of retraction. The average rate of advance, as calculated from the time cytoplasm began to invade the lamella until it reached half the distance to the tip of the filopodium, was $4.68 \pm 0.36 \mu \mathrm{m} / \mathrm{min}(n=44)$. The thickened portion of the filopodium often sprouted new filopodia and lamellipodia, thereby resembling a growth cone. After the advancing front of cytoplasm reached the tip of the filopodium, the process began to elongate (not illustrated). First, it circled the cell body of the adjacent neuron and then looped back to grow along its own surface. Although processes formed in this manner only grew over the surfaces of cells, they eventually became very long, as is typical of axons.

The cell bodies of neurons typically were asymmetric, with the nucleus displaced to one side of the main mass of cytoplasm (Fig. 4), but neurons had filopodia around their entire circumferences. A filopodium that contacted another cell initiated the 

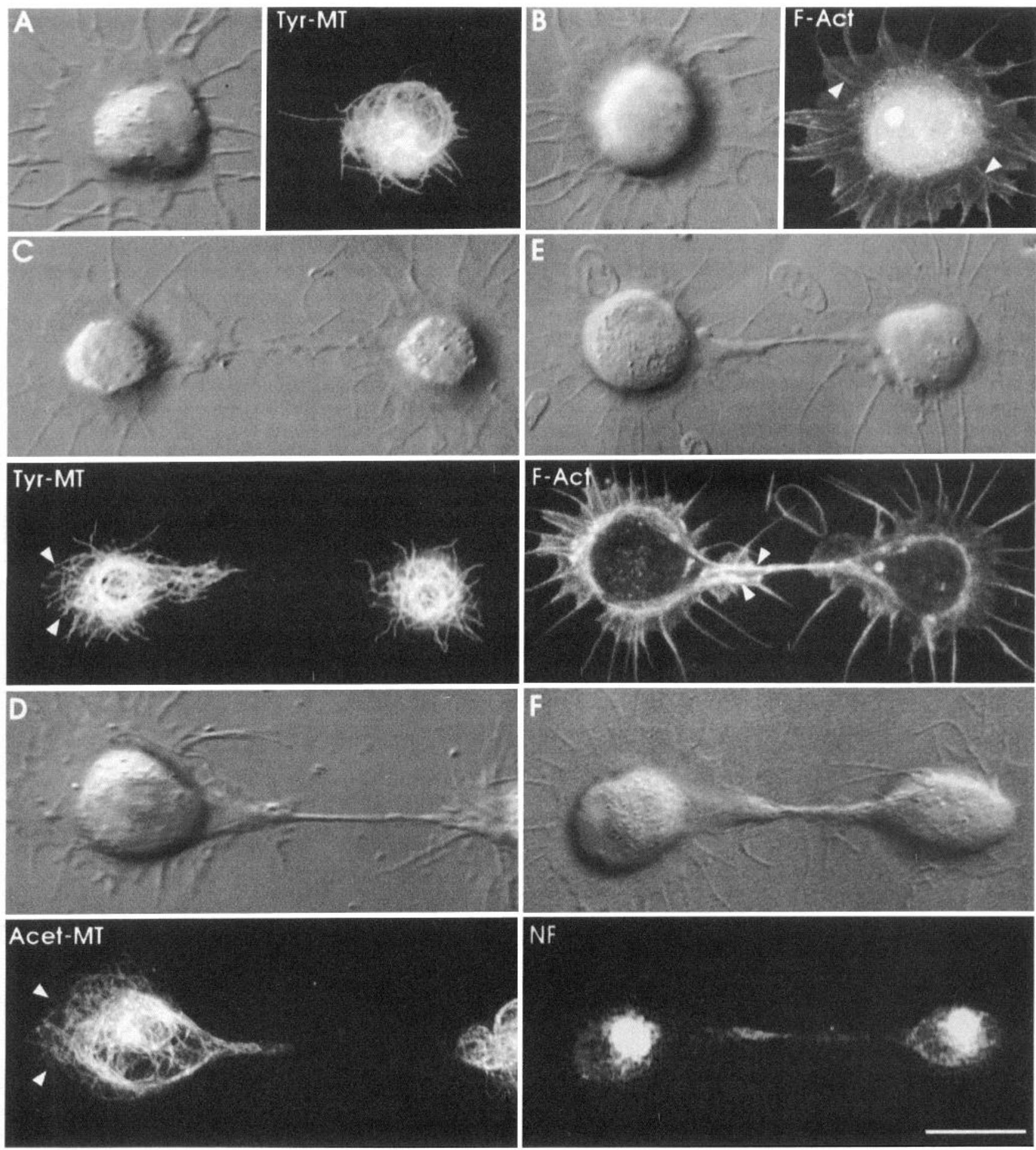

Figure 5. Organization of the cytoskeleton in neurons prior to $(A$ and $B)$ and during $(C-F)$ the initiation of neurite outgrowth on polyornithine. Fluorescence images show neurons stained with labels for specific cytoskeletal proteins: $T y r-M T$, microtubules containing tyrosinated-tubulin; $A c e t$ $M T$, microtubules containing acetylated-tubulin; $F-A c t$, actin filaments; $N F$, neurofilaments. In neurons that had not begun to form neurites, microtubules were largely confined to the perinuclear region $(A)$. The actin filaments that formed the cores of filopodia extended through the lamella (arrowheads in $B$ ) and appeared to terminate near the outer margin of the perinuclear cytoplasm. In $B$, the brightness of the perinuclear cytoplasm is due to autofluorescence (compare with $E$, where autofluorescence was reduced with sodium borohydride). DIC images in $A$ and $B$ show neurons $\sim 20 \mathrm{~min}$ before fixation. In $C-F$, neurons were fixed $2-6 \mathrm{~min}$ after cytoplasm had begun to invade a filopodium that had contacted another cell. The DIC images show the neurons $\sim 20$ sec prior to fixation. The column of cytoplasm that invaded a filopodium contained tyr-MT $(C)$, acet-MT $(D)$, and neurofilaments $(F)$. The interior of the column was actin poor $(E)$, but it was surrounded by a region rich in actin filaments $($ arrowheads). In $C$ and $D$, microtubules were present not only in the perinuclear cytoplasm and in the cytoplasm that invaded the filopodium, but also in a region on the left side of the cell body (arrowheads) that corresponds to the location of the cell body before neurite formation began. Scale bar, $10 \mu \mathrm{m}$. 

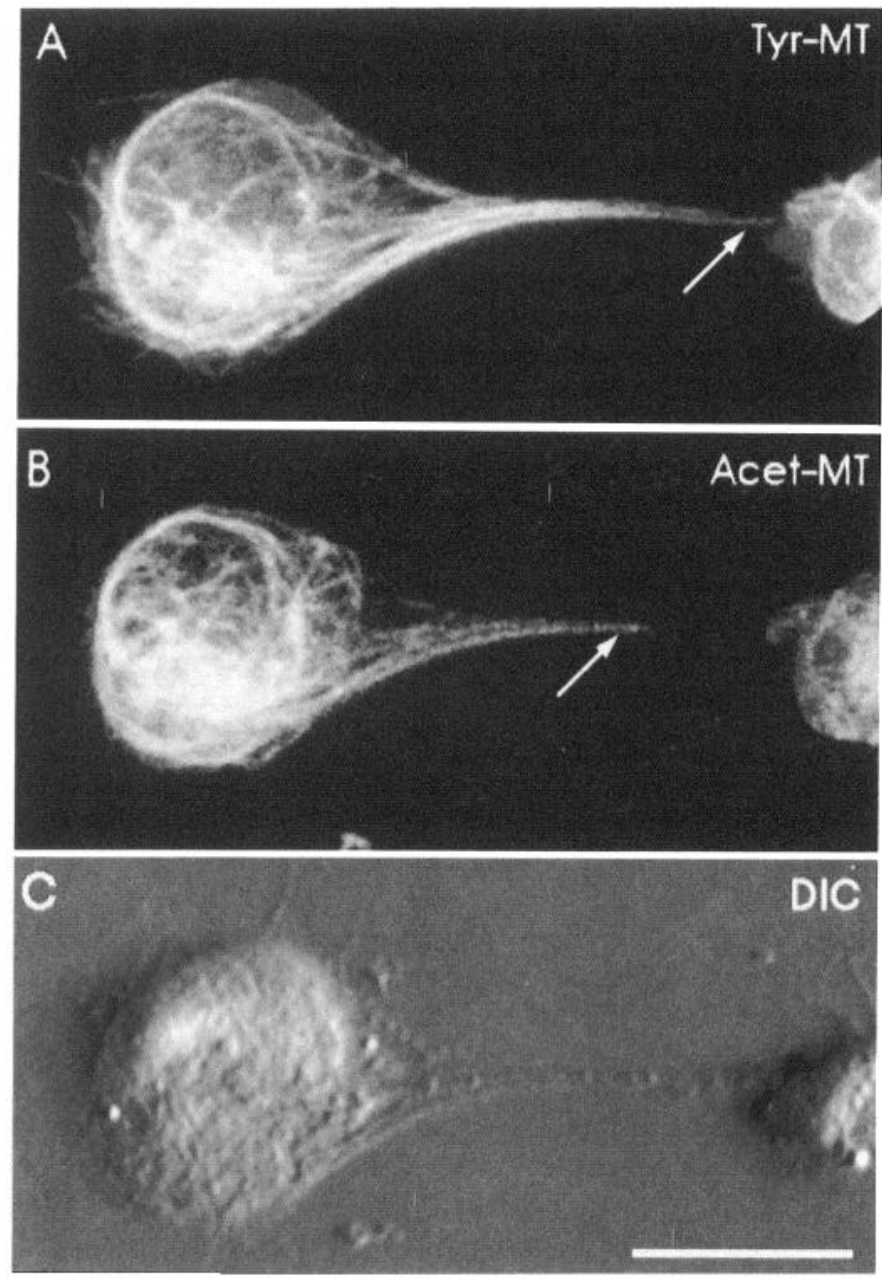

Figure 6. Distributions of dynamic and stable microtubules in developing neurites. Neurons growing on polyornithine were double-labeled with antibodies against tyrosinated-tubulin, a marker for dynamic microtubules $(T y r-M T)$, and antibodies against acetylated-tubulin, a marker for stabilized microtubules (Acet-MT). Fluorescence and DIC images were collected by laser scanning confocal microscopy after the cells were fixed. Note that dynamic microtubules extend farther distally in the neurite than do stable microtubules (arrows). Scale bar, $10 \mu \mathrm{m}$.

movements of cytoplasm that led to neurite formation regardless of its position relative to the orientation of the cell body. However, if the filopodium was not aligned with the cell axis, as defined by a line bisecting the nucleus and main mass of cytoplasm, then the nucleus and cytoplasm usually rotated so as to align the cell axis with the filopodium (Fig. 4). The nucleus and cytoplasm appeared to rotate as a coherent unit within the lamella, which remained stationary. They usually began to rotate only after cytoplasm had begun to invade the filopodium. However, the cell bodies of some neurons were rotating when neurite formation began. In these neurons, the cell body either continued to rotate in the same direction, or reversed and rotated in the opposite direction, until the cell axis became aligned with the developing neurite. When a neuron formed two neurites, its cell body typically rotated so as to center the cell axis between the two neurites. Thus, the interactions of neurons with other cells can determine both the sites around their perimeters at which neurites form and the orientations of their cell bodies.
The actin cores of filopodia are replaced by cytoplasm containing microtubules and neurofilaments

Microtubules, neurofilaments, and actin filaments were localized by fluorescence imaging methods in neurons that were fixed and stained at different times during neurite formation. Microtubules were labeled with antibodies specific for tyrosinated tubulin, the form of tubulin present in newly assembled microtubules (tyr-MT; Wehland et al., 1983), or acetylated tubulin, a posttranslationally modified form of tubulin that often is present in microtubules that have become stabilized (acet-MT; Piperno et al., 1987). Neurofilaments were labeled with antibodies against the low-molecular-weight neurofilament protein, and actin filaments with rhodamine phalloidin. Neurons grown on polyornithine were used because they formed neurites only after contacting other cells and because movements of cytoplasm could be resolved more easily in them than in neurons grown on laminin. All neurons described here had been in culture for at least $3 \mathrm{hr}$ without dividing, suggesting that they were postmitotic when plated.

In neurons that had not yet begun to form neurites, microtubules and neurofilaments were largely confined to the perinuclear region, although a few tyr-MT extended into the lamella or the proximal portions of filopodia (Fig. 5A). The distribution of acet-MT (not illustrated) was similar to the distribution of tyr-MT (Fig. 5A), except that acet-MT rarely extended into lamellae. Neurofilaments were present throughout the perinuclear cytoplasm and, in many cells, there was a dense accumulation of neurofilaments at the center of the main mass of cytoplasm (similar accumulations can be seen in Fig. $5 F$ ). Actin filaments were concentrated in the lamella and in filopodia (Fig. $5 B$ ). The bundles of actin filaments that form the cores of filopodia (Tosney and Wessells, 1983) emanated from the outer margin of the perinuclear cytoplasm, suggesting that they potentially could interact with components of the perinuclear cytoskeleton.

In neurons that had contacted another cell and begun to form neurites, the distributions of tyr-MT (34 neurons), acet-MT (18 neurons), and neurofilaments ( 14 neurons) corresponded closely with the distribution of cytoplasm as seen by video microscopy. Portions of the lamella or of a filopodium that appeared thick because they had been invaded by cytoplasm contained microtubules and neurofilaments, whereas portions that appeared thin generally did not (Fig. $5 C, D, F$ ). However, there were some differences in the distributions of the three components of the cytoskeleton. The numbers of tyr-MT and acet-MT declined with increasing distance from the cell body (Fig. $5 C, D$ ), but the density of neurofilaments often appeared to be higher near the leading edge of the cytoplasm than in more proximal regions ( 10 of 14 neurons; Fig. $5 F$ ). Tyr-MT invariably extended to the leading edge of the cytoplasm and, sometimes, a single tyr-MT or a small bundle of tyr-MT extended a few micrometers beyond the leading edge, into portions of a filopodium that remained relatively thin. However, acet-MT and neurofilaments appeared to extend only to the leading edge of the cytoplasm or even a few micrometers less distally.

To compare the distributions of acet-MT and tyr-MT in individual neurons, in three experiments cells were double-labeled with antibodies for both forms of tubulin. Neurons that had begun to form neurites were identified after the cultures were fixed and stained. Staining for acet-MT typically stopped a few micrometers more proximally than did staining for tyr-MT (Fig. 6). This differential distribution of tyr-MT and acet-MT is just 

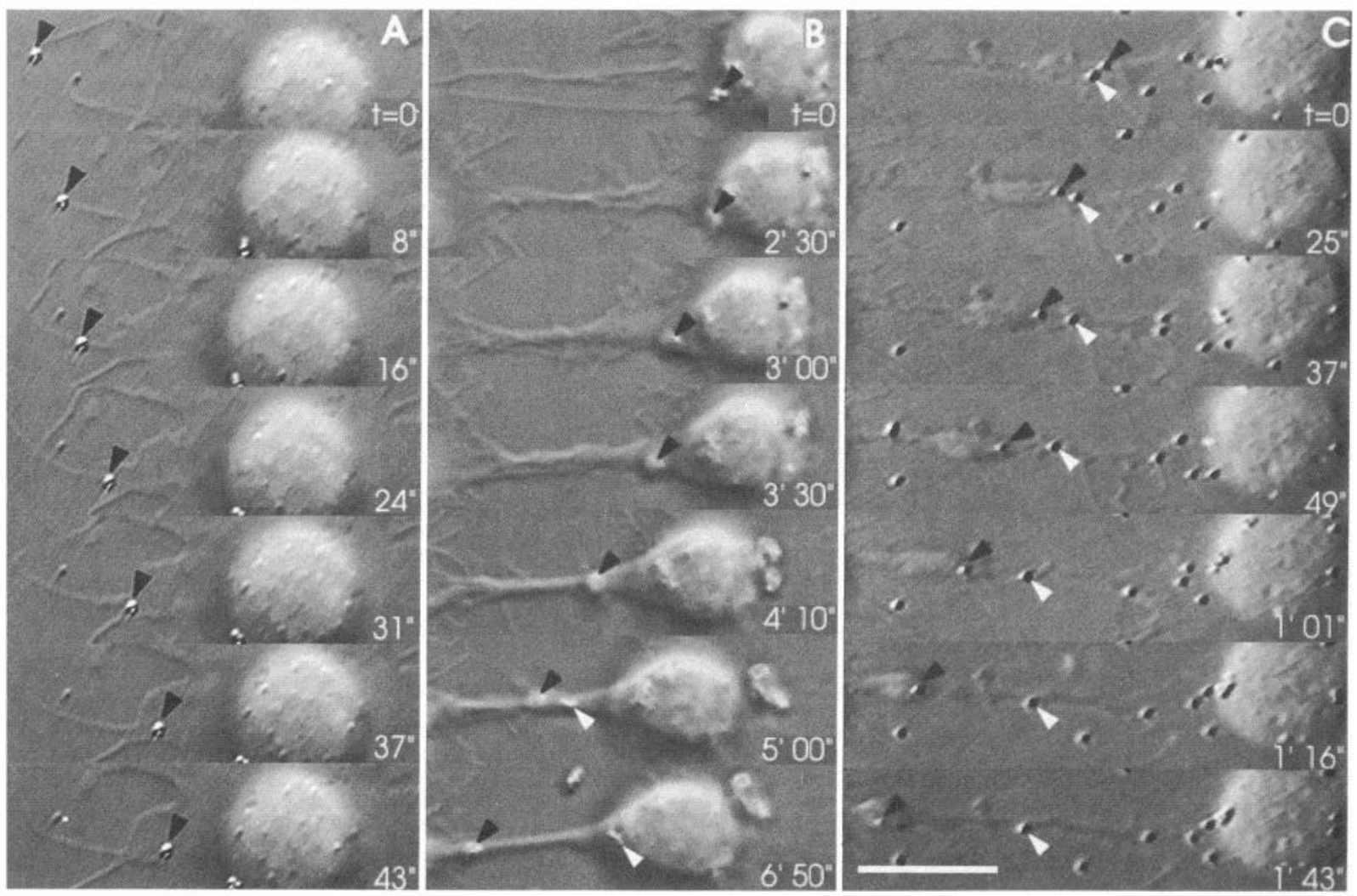

Figure 7. Movements of small beads on the surface of neurons prior to $(A)$ and during $(B$ and $C)$ the initiation of neurite outgrowth on polyornithine. In $A$, a small bead (arrowheads) moves retrogradely over the surface of a filopodium and then over the lamella surrounding the cell body. In $B$, a cluster of beads (black arrowheads) that initially is attached to the cell body is carried outward along a filopodium that has contacted another cell and is being invaded by cytoplasm; individual beads can be resolved in the first image but not in subsequent images because they leave the plane of focus. A cluster of beads on a more proximal part of the developing neurite moves retrogradely (white arrowheads beginning at 5 '00"). The sequence of images in $C$ illustrates the relative movement of beads attached to different parts of a neuron during invasion of a filopodium by cytoplasm. The bead near the leading edge of the cytoplasmic protrusion (black arrowheads) moves anterogradely at the same rate as the cytoplasm, but the bead on a more proximal part moves forward less rapidly (white arrowheads). The beads on the lamella are stationary or move retrogradely. Scale bar, $10 \mu \mathrm{m}$.

as expected if microtubules are oriented such that their "plus" ends, the preferential ends for polymerization, are located distally, as is true of microtubules in mature axons (Burton and Paige, 1981; Heidemann et al., 1981; Robson and Burgoyne, 1989).

Comparison of the distributions of actin filaments in neurons prior to and during invasion of filopodia by cytoplasm suggested that the cores of filopodia shortened as they were invaded. Before filopodia were invaded, their cores extended through the lamella to the outer margin of the perinuclear cytoplasm, where they appeared to terminate or merge with perinuclear actin filaments (Fig. $5 B, E$ ). The cores of filopodia were not visible in portions of a lamella that had been invaded by cytoplasm (Fig. $5 E$ ). The concentration of actin filaments within the cytoplasm was low, as in perinuclear cytoplasm, although the leading edge of the cytoplasm was surrounded by a region that was rich in actin filaments. The core of the filopodium that had initiated movement of the cytoplasm appeared to merge with the actin filaments at the leading edge of the cytoplasm.

\section{Movements of cytoplasm are accompanied by movements of components of the plasma membrane}

To ascertain whether the movements of cytoplasm that lead to the formation of neurites are accompanied by movements of molecules in the surface membrane, small $(0.5-1.0 \mu \mathrm{m})$ poly- styrene beads were perfused onto the surfaces of neurons just as they were beginning to form neurites (10 experiments on cultures grown on polyornithine). The beads were coated with polyornithine, which, because it is positively charged, is likely to interact with a variety of negatively charged molecules in the surface membrane. Before neurite formation began, beads attached to the surface membrane surrounding the perinuclear cytoplasm moved very little. However, when a filopodium was invaded by cytoplasm, beads attached to the membrane surrounding the affected part of the cytoplasm sometimes were carried outward with the cytoplasm (Fig. 7B). Beads located near the leading edge of the cytoplasm moved in synchrony with the leading edge, moving anterogradely when the leading edge advanced (Fig. $7 B, C$ ) and retrogradely when it receded (not illustrated). Beads located farther back from the leading edge also underwent intermittent anterograde and retrograde movements (Fig. $7 B, C$ ) that appeared to be correlated with those of the subjacent cytoplasm. It is not possible in every instance to be certain that a bead that attached to the surface of a neuron remained on the surface. Indeed, some beads were endocytosed. However, in many instances, it was obvious from the plane of focus that a bead was on the surface of a neuron, not inside it. This was particularly clear for clusters of beads (Fig. 7B).

Filopodia that were not being invaded by cytoplasm transported beads that attached to their surfaces retrogradely (Fig. 
$7 A)$ at an average rate of $10.76 \pm 0.57 \mu \mathrm{m} / \mathrm{min}(n=22)$. Beads visualized in real time appeared to move continuously, not intermittently. Filopodia also transported side branches and remnants of lamellipodia retrogradely at approximately the same rate, and at higher magnification $(10,000 \times)$ there appeared to be a continuous retrograde How of material within filopodia. Retrograde movement of particles on the surfaces of filopodia and lamellipodia as well as retrogradc cortical flow have been seen in other systems (Abercrombie et al., 1970; Bray, 1970; Fisher et al., 1988; Forscher and Smith, 1988, 1990; Sheetz et al., 1989; Theriot and Mitchison, 1992), but the relationship between these phenomena remains controversial. Smaller beads have been reported to move anterogradely on filopodia and lamellipodia (Sheetz et al., 1990; Forscher et al., 1992), but only retrograde movements were observed in the present study.

Neurite formation can be initiated by contact of a flopodium with a large polyornithine- or laminin-coated bead

The observation that cytoplasm invaded filopodia when they attached to another cell or a laminin-coated substrate, but not a polyornithine-coated substrate, suggested that adhesion mediated by natural cell adhesion molecules might be necessary to initiate neurite outgrowth. To test this hypothesis, large $(\sim 10$ $\mu \mathrm{m})$ polystyrenc bcads coated with either polyornithine alone or both polyornithine and laminin were added to cultures of neurons grown on polyornithine to see if they induced neurite formation. As might be expected from the results described above, cytoplasm invaded filopodia that contacted laminincoated beads (Fig. 8). However, cytoplasm also invaded filopodia that contacted beads coated only with polyornithine. When a filopodium contacted a bead coated with either type of substrate molecule, it straightened, suggesting that it had detached from the coverslip and was under tension. This often was followed by invasion of the filopodium with cytoplasm ( 13 neurons in 8 experiments with laminin-coated beads and 21 neurons in 12 experiments with polyornithine-coated beads). Cytoplasm advanced at instantaneous rates similar to the rate of advance in filopodia that contacted other cells (up to $\sim 9 \mu \mathrm{m} / \mathrm{min}$ ), but the average rate of movement was slower $(2.22 \pm 0.47 \mu \mathrm{m} / \mathrm{min}$; $n=10$ ) becausc there were more frequent reversals of direction. Although beads coated with either type of substrate molecule could initiate movement of cytoplasm, not every filopodium that contacted a bead was invaded (see below).

In addition to showing that neurite formation can be initiated by either natural or artificial adhesion molecules, these experiments with beads also provided some novel insights about the relationship between filopodial adhesion and movement of perinuclear cytoplasm. First, in order to initiate movement of cytoplasm, beads had to be attached to the substrate. When beads that were floating in the medium landed on the surfaces of filopodia they did not initiate movement of cytoplasm, but instead were transported retrogradely to the cell body. These observations suggest that the tips of filopodia may have to be anchored to initiate movement of cytoplasm.

Second, cytoplasm continued to move forward in a filopodium only as long as the bead to which it was attached remained stationary. When the leading edge of the cytoplasm reached the bead, the bead usually began to move, suggesting that it had detached from the substrate. The bead then was transported retrogradely over surface of the filopodium to the cell body (Fig. 8 , right) and the cytoplasm receded into the cell body at the same rate (average rate $=3.49 \pm 0.68 \mu \mathrm{m} / \mathrm{min} ; n=9$ ). Filopodia usually shortened to some extent while the cytoplasm and bead moved retrogradely, but sometimes they remained the same length or even elongated. In two instances, a bead that had begun to be transported retrogradely stopped moving, possibly because it reattached to the substrate. When the bead stopped moving, the cytoplasm stopped receding. The observation that the retrograde movements of beads and cytoplasm are correlated suggests that they are produced by related mechanisms.

Finally, both the initial invasion of the filopodium by cytoplasm and the subsequent retraction of cytoplasm back into the center of the cell were accompanied by movements of the cell body. The cell body shifted toward the base of the filopodium while the filopodium was being invaded by cytoplasm (Fig. 8 , left) and, when the cytoplasm retracted, the cell body returned to its original position in the center of the lamella (Fig. 8, right). In some neurons, the nucleus and perinuclear cytoplasm subsequently rotated within the lamella by up to $360^{\circ}$, carrying the bead attached to the surface with them (not illustrated).

IRM shows that neurite formation is associated with particular patterns of attachment

Neurons growing on both polyornithine and laminin were examined with IRM in order to determine how closely different parts of the cell were attached to the substrate. In IRM images, areas of the cell membrane that are separated from the substrate by less than $\sim 50 \mathrm{~nm}$ appear darker than the background, whereas areas that are more than $\sim 100 \mathrm{~nm}$ above the substrate appear lighter than the background or are not visualized (Izzard and Lochner, 1976). A laser scanning confocal microscope was used for these observations because preliminary experiments showed that laser scanning IRM provides higher-resolution images than conventional IRM and is less damaging to neurons, making it possible to collect time-lapse records for longer periods of time. In addition, cells could be simultaneously visualized with DIC optics.

Neurons plated on polyornithine were closely apposed to the substrate (Fig. 9A,B). Filopodia typically were in close contact with the substrate along most of their lengths, although their distal ends sometimes were not as close. However, when the distal end of a filopodium contacted another cell (Fig. 9A,B) or a bead (not illustrated), the rest of the filopodium often detached from the substrate, as indicated by its image changing from dark to light. Filopodia that had attached to a cell or bead, and detached from the substrate, often were invaded by cytoplasm (Fig. 9B). Portions of the filopodium that had been invaded subsequently reattached to the substrate (Fig. 9B). Even filopodia that were suspended so far above the substrate that they were invisible by IRM sometimes were invaded by cytoplasm (not illustrated).

Neurons attached to substrates coated with laminin (Fig. 9C) less closely than to substrates coated with polyornithine. Filopodia typically were loosely apposed to the substrate along most of their lengths. However, the tips of filopodia often were closely apposed (Fig. 9D). This pattern of attachment seems to promote neurite formation because filopodia of neurons growing on laminin were rapidly invaded by cytoplasm.

Although IRM shows how close different parts of a cell are to a substrate, it does not necessarily show how firmly they are attached. However, in time-lapse IRM sequences of neurons grown on laminin, parts of the cell that were firmly attached could be recognized because they remained attached when other parts of the cell moved. For example, when a filopodium emerg- 


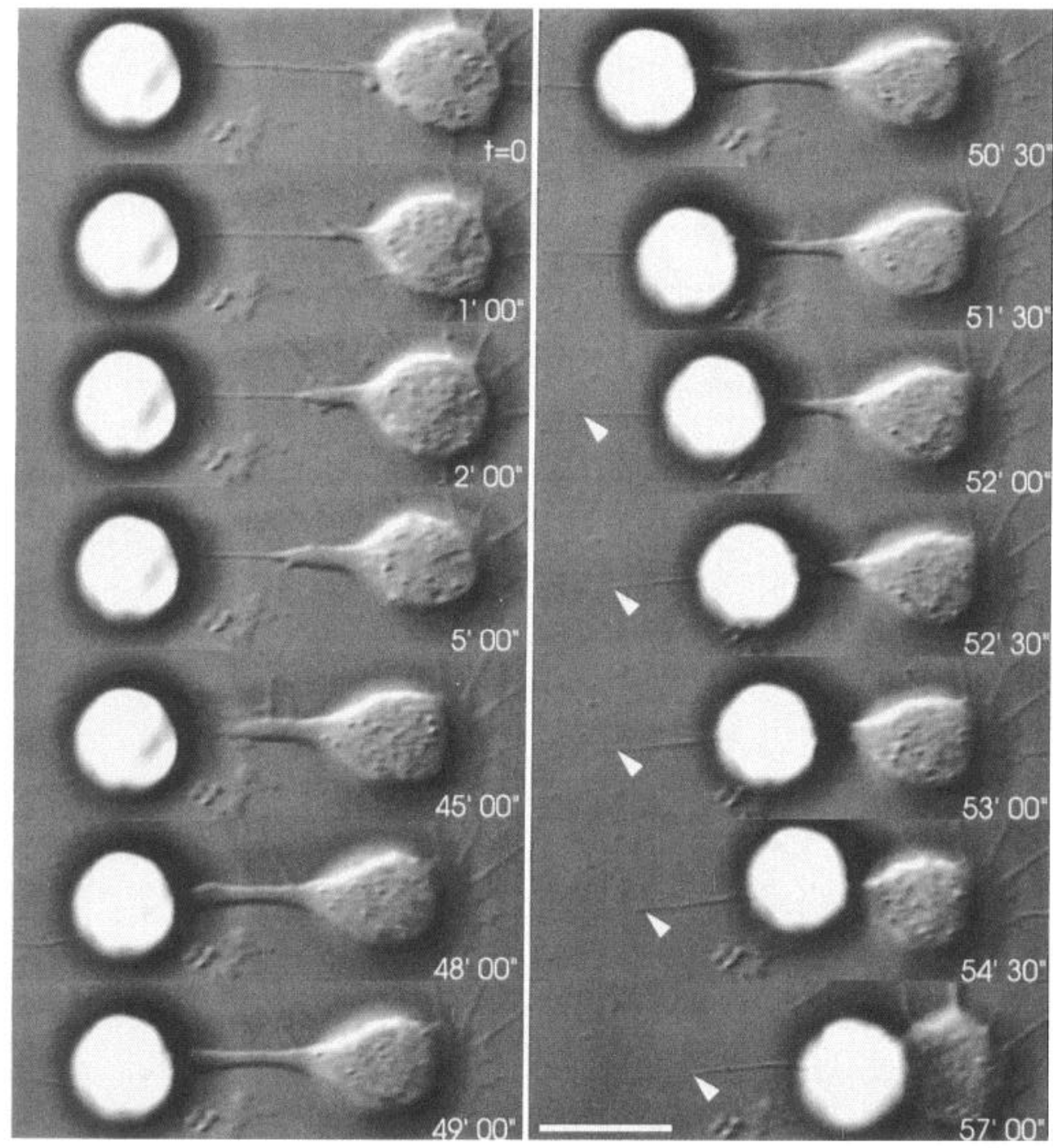

Figure 8. Movement of cytoplasm initiated by contact of a filopodium with a large polystyrene bead. Between $t=0$ and $49^{\prime} 00^{\prime \prime}$, the filopodium contacting the bead was invaded by a column of cytoplasm and, simultaneously, the cell body moved toward the base of the filopodium. Between $50^{\prime} 30^{\prime \prime}$ and $51^{\prime} 30^{\prime \prime}$, the bead detached from the substrate. Then the column of cytoplasm retracted into the cell body, carrying the bead with it, and the cell body returned to its original position. The filopodium shortened when the cytoplasm retracted (arrowheads), but in other experiments filopodia remained the same length or elongated. In this experiment, the bead was coated with both polyornithine and laminin, but identical movements of cytoplasm were initiated by beads coated with polyornithine alone. Scale bar, $10 \mu \mathrm{m}$. ing from a neurite was pulled laterally by movement of the neurite, the tip of filopodium, which appeared dark by IRM, remained attached to the substrate and did not move. Also, when an entire neurite was pulled laterally by movements of other parts of the cell, portions of the neurite that appeared dark remained attached to the substrate, becoming the tips of branches that were progressively pulled out of the neurite as it moved. On polyornithine, the closeness of apposition may not reflect the strength of attachment since filopodia that contacted a bead or a cell detached from the substrate even though the darkness of their IRM images suggested that they were as closely apposed to the substrate as the tips of filopodia were on laminin.

\section{Discussion}

The initial outgrowth of neurites from the cell bodies of single sympathetic neurons was investigated with time-lapse video microscopy in order to monitor movements of neuronal cytoplasm that lead to the formation of neurites and to determine the concomitant pattern of neuronal attachment to the growth substrate. To correlate the movements of cytoplasm with changes in the cytoskeleton, neurons first were examined by video microscopy and then were fixed and stained with labels for actin filaments, microtubules, or neurofilaments. The results reveal that the formation of neurites involves invasion of filopodia by cytoplasm from the perinuclear region and that this process can be initiated by contact of the tip of a filopodium with another cell, a large bead, or a substrate coated with laminin. In many ways, the events that occur in neurons during the initiation of neurite outgrowth are analogous to events that occur in growth cones during neurite elongation. Current ideas about the mechanisms of growth cone motility are helpful here in interpreting the mechanisms of neurite formation. At the same time, the present findings provide new information about the substrate interactions that initiate movement of neuronal cytoplasm, information that may be relevant to understanding the mechanisms of neurite elongation.

\section{Neurite formation begins with invasion of filopodia by cytoplasm from the perinuclear region}

The formation of a neurite always involved invasion of a filopodium by cytoplasm from the perinuclear region. This was true both for spontaneous neurite formation in cultures grown on laminin, and for neurite formation induced by contact of a filopodium with another cell or a large bead in cultures grown on polyornithine. Neurons also formed lamellipodia, but lamellipodia were invaded by cytoplasm and incorporated into 

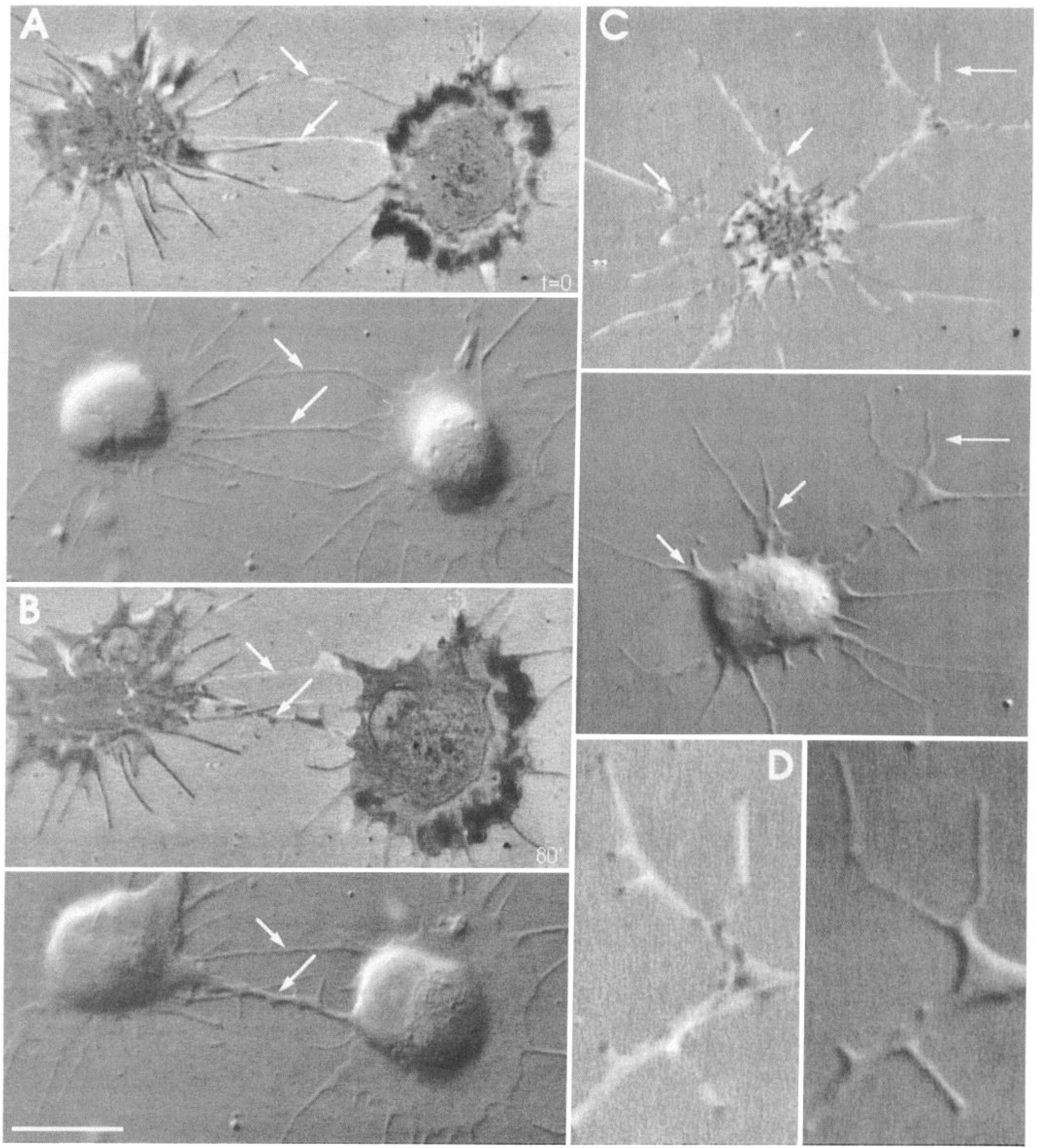

Figure 9. Interactions of neurons with the growth substrate during the initiation of neurite outgrowth as visualized by IRM and DIC laser scanning microscopy. In IRM images, areas of the cells that are closely apposed to the substrate appear dark while those that are less close appear light. The left column shows a pair of neurons on polyornithine before $(A)$ and after $(B)$ filopodia are invaded by cytoplasm. Most filopodia were closely apposed to the substrate and were not invaded by cytoplasm. However, two filopodia that emerged from the neuron on the right were only loosely apposed (arrows), as evident from the brightness of the IRM images (upper panels) as well as from their movement relative to the substrate. These filopodia were invaded by cytoplasm $(B)$. $C$ shows a neuron growing on laminin after some of its filopodia have been invaded by cytoplasm (arrows). The filopodia indicated by the long arrow are shown at higher magnification in $D$. Note that these filopodia are loosely apposed to the substrate along most of their lengths, but that their tips are closely apposed $(D, l e f t)$. Scale bar, $10 \mu \mathrm{m}$. 
neurites only when they lay along the sides of filopodia. Although the present findings pertain to sympathetic neurons, identical results were obtained in parallel studies on dorsal root ganglion neurons (Smith and Munro, 1990).

The formation of a neurite seems to involve the migration of an entire domain of the perinuclear cytoplasm outward along a path defined by a filopodium. Microtubules, neurofilaments, and organelles invaded the filopodium simultaneously, suggesting that cytoplasm moves as a coherent unit, and small beads attached to the surface membrane surrounding the cytoplasm moved in synchrony with the cytoplasm. Since the membrane molecules to which the beads were attached probably were coupled to cortical actin filaments (Fisher et al., 1988; Forscher and Smith, 1990; Kucik et al., 1991), this observation suggests that cortical actin filaments accompanied cytoplasm as it moved. When neurite formation was induced by contact with another cell, the distal end of the filopodium remained at approximately the same distance from the cell body while it was being invaded by cytoplasm. The bundle of actin filaments forming the core of the filopodium appeared to extend proximally only to the leading edge of the cytoplasm, suggesting that the core progressively shortened. The core may shorten by depolymerization of actin filaments at its proximal end (Forscher and Smith, 1988; Okabe and Hirokawa, 1991).

The rate at which cytoplasm advanced (average rate $=4.68$ $\mu \mathrm{m} / \mathrm{min}$ ) is comparable to the rate of microtubule polymerization in neurons and other types of cells (Schulze and Kirschner, 1983; Baas and Ahmad, 1992), consistent with the possibility that the advance of microtubules was due to growth of microtubules by polymerization at their distal ends. However, preliminary results of experiments that will be described in a subsequent report show that stable microtubules can invade filopodia even when tubulin polymerization is prevented (Smith, 1992, and unpublished observations). This observation suggests that neurite formation involves translocation of microtubules as well as polymerization. Since neurofilaments are thought to be stable polymers (Shaw, 1991), their rapid appearance in developing neurites probably is due to transport rather than polymcrization. Indeed, neurofilaments often were concentrated more highly in distal than proximal parts of the cytoplasmic protrusion, suggesting that they were carried outward as cytoplasm advanced.

Filopodia that contacted another cell initiated the movements of cytoplasm that led to the formation of neurites regardless of their locations relative to the orientation of the cell body. Before neurite outgrowth, the nucleus typically was displaced to one side of the main mass of cytoplasm. If the filopodium that initiated neurite formation was not located on the side of the cell containing the main mass of cytoplasm, then the cell body usually rotated so as to bring the cytoplasm to the base of the filopodium. Thus, the interactions of neurons with other cells can determine the orientation of their cell bodies as well as the sites from which neurites emerge. Studies in a wide variety of systems have shown that neurites are guided during their growth by interactions with other cells, but the initial trajectories of neurites were believed to be determined by patterns intrinsic to neuronal cell bodies (reviewed by Jacobson, 1978).

Neurite formation depends on a particular pattern of attachment to a substrale but doe's not require natural cell adhesion molecules

It is well known that neurons form neurites rapidly when grown on laminin, but form neurites slowly, or not at all, when grown on polyornithine (Letourneau, 1975; Collins, 1978a: Baron-Van Evercooren, 1982; Manthorpe et al., 1983). Consistent with these observations, the present experiments show that cytoplasm rapidly invaded filopodia of neurons plated on laminin, or filopodia that contact large laminin-coated beads, but not filopodia attached to a polyornithine-coated coverslip. However, cytoplasm did invade filopodia when they contacted large, polyornithine-coated beads. This finding was unexpected since it indicated that adhesion mediated by either natural or artificial adhesion molecules can initiate the movements of cytoplasm that lead to the formation of neurites.

Experiments in which neurons were observed with both IRM and DIC optics suggest that invasion of filopodia by cytoplasm depends on a specific pattern of substrate attachment. Filopodia of neurons growing on laminin were closely apposed to the substrate only at their tips and cytoplasm rapidly invaded them. By contrast, filopodia of neurons growing on polyornithine were closely apposed to the substrate along most of their lengths and were invaded by cytoplasm only after they contacted a threedimensional object, such as a cell or a large bead, and detached from the substrate. These findings suggest that cytoplasm can invade filopodia when only their distal tips are attached to a substrate, but not when they are closely apposed to a substrate along their entire lengths.

Several observations suggest that filopodia must be under tension in order to initiate the movements of cytoplasm that lead to the formation of neurites. Cytoplasm did not invade filopodia immediately after they contacted another cell or a bead, but only after the filopodium had detached from the substrate and begun to straighten. The close temporal relationship between straightening of the filopodium and the initiation of cytoplasmic movement suggests that movement of cytoplasm actually is initiated by the tension that develops in the filopodium. Indeed, it appears that filopodia must remain under tension in order for cytoplasm to continue to move outward because the movement of cytoplasm reversed if the object to which the filopodium was attached subsequently detached from the substrate. Also, cytoplasm did not invade filopodia when they attached to beads that were not bound to the substrate.

Additional support for the idea that tension might be important in initiating neurite formation comes from studies that showed that dorsal root ganglion neurons can be induced to form neurites by attaching a pipette to their margins and pulling outward (Bray, 1984; Zheng et al., 1991). The forces needed to initiate neurite formation typically were between 100 and 200 $\mu$ dyn (Zheng et al., 1991), approximately twice the force exerted by a single filopodium (50-90 $\mu$ dyn; Heidemann et al., 1990), but occasionally forces of less than $100 \mu$ dyn were sufficient.

The idea that filopodia must develop tension to initiate movement of cytoplasm provides a possible explanation as to why filopodia were not invaded by cytoplasm when they were attached to a substrate along their entire lengths but were invaded when only their tips were attached. The proximal portions of a filopodium may have to be free to move in order for tension to develop. However, close apposition of the tip of the filopodium to a substrate may not be obligatory. IRM studies of other types of neurons grown on laminin and several additional substrates that promote neurite outgrowth show that the attachment patterns of filopodia differ and that the tips of filopodia are not consistently closely apposed to the substrate (Gundersen, 1988; Drazba et al., 1992, unpublished observations). Whether these 
Figure 10. Two possible mechanisms for moving cytoplasm into a filopodium. Both models assume that actin filaments within filopodia move retrogradely until their distal ends become distally anchored, and that the overall lengths of the actin filaments are maintained by polymcrization at their distal ends and depolymerization at their proximal ends. Small beads that attach to the surface of the filopodium also move retrogradely because they become coupled to actin filaments through interactions with membrane proteins. When the distal ends of actin filaments become anchored (depicted here occurring after contact with a large bead), their retrograde flow is prevented. The boxes are enlarged (below) to show how this might lead to invasion of the filopodium by cytoplasm. Model $I$ is based on the idea that actin filaments modulate microtubule polymerization. Microtubules are able to polymerize and invade the filopodium only when actin filaments become distally anchored and begin to shorten because of continued depolymerization at their proximal ends. Model 2 is based on the idea that actin filaments are transported retrogradely by myosin molecules attached to a component of the perinuclear cytoskeleton (depicted here as perinuclear actin filaments cross-linked to microtubules). When actin filaments in the filopodium are anchored distally, these myosin molecules pull components of the perinuclear cytoskeleton into the filopodium. For further explanation, see Discussion.
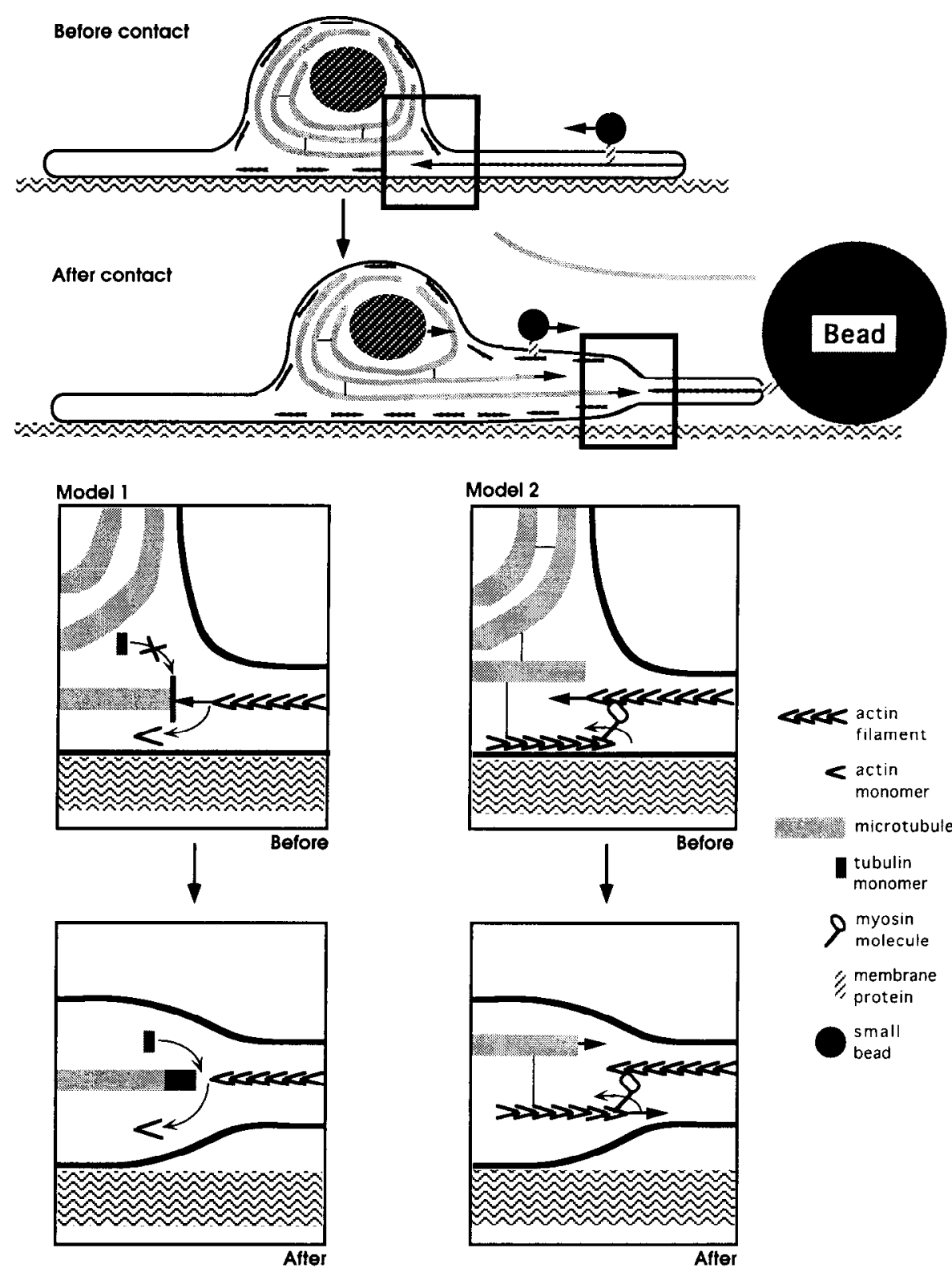

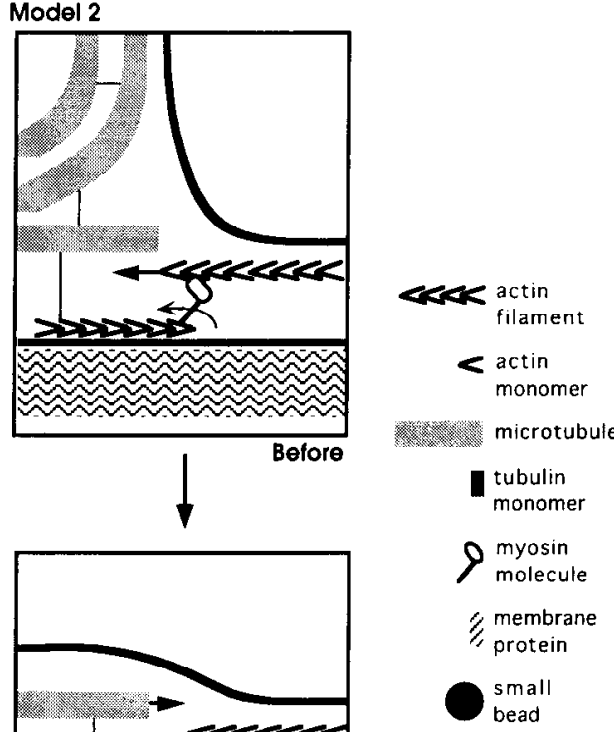

patterns of attachment allow filopodia to develop tension and be invaded by cytoplasm remains to be determined.

\section{Cytoskeletal mechanisms involved in neurite initiation: two hypotheses}

The present findings show that neurite formation by sympathetic neurons involves invasion of filopodia by cytoplasm from the perinuclear region and that this begins when the tip of a filopodium becomes anchored to a substrate and is put under tension. Two models showing how different components of the cytoskeleton might interact to produce these movements of cytoplasm are illustrated in Figure 10. Both models are based on the experimental observation that filopodia contain material that appears to flow retrogradely (Forscher and Smith, 1988; Sheetz et al., 1990, 1992; Okabe and Hirokawa, 1991; present results) and on the hypothesis that actin filaments are included in this retrograde flow (Wang, 1985; Fisher et al., 1988; Forscher and Smith, 1988; Sheetz et al., 1992; Theriot and Mitchison, 1992). It is thought that the overall lengths of actin filaments are maintained by continuous polymerization at their distal ends and depolymerization at their proximal ends (reviewed by Sheet $z$ et al., 1992). Both models also incorporate the idea that molecules that mediate adhesion can become coupled to actin filaments and that this is why small beads that attach to the surfaces of filopodia are transported retrogradely (Fisher et al., 1988; Forscher and Smith, 1990; Sheetz et al., 1990, 1992). Here, it is assumed that the distal ends of actin filaments become anchored when the tip of a filopodium adheres to another cell, a large bead, or a laminin-coated substrate. This impedes the retrograde flow of actin and actin filaments progressively shorten because they no longer polymerize at their distal ends but continue to depolymerize at their proximal ends.

The first model (Fig. 10, Model 1) is based on the idea that actin filaments modulate microtubule polymerization (Buxbaum and Heidemann, 1988; Forscher and Smith, 1988; Goldberg et al., 1991; Heidemann et al., 1991). Model 1 suggests that microtubules normally are unable to enter filopodia because they contain a core of actin filaments along their entire lengths. 
When the distal ends of actin filaments become anchored to a substrate and their retrograde flow is prevented, continued depolymerization at their proximal ends causes them to shorten. This allows microtubules to polymerize and invade the filopodium. Other components of perinuclear cytoplasm may be carried into the filopodium by transport along microtubules.

The second model (Fig. 10, Model 2) suggests that perinuclear cytoplasm is pulled into the filopodium by the same molecular motors that move actin filaments retrogradely prior to neurite formation. Model 2 portrays these motors as myosin molecules that are directly or indirectly attached to components of the perinuclear cytoskeleton. Whether the myosin molecules move actin filaments retrogradely or perinuclear cytoplasm anterogradely depends on whether or not the distal ends of actin filaments are anchored to the substrate. An attractive feature of this model is that it explains why filopodia are put under tension when their tips attach to a substrate and why the entire cell body moves toward the base of a filopodium that is being invaded by cytoplasm.

The elongation of neurites also involves protrusion of cytoplasm containing microtubules and organelles into a domain that is composed predominantly of actin, and models similar to those presented here have been proposed to explain how growth cones migrate across a planar substrate (Letourneau, 1982; Bray and Chapman, 1985; Mitchison and Kirschner, 1988; Smith, 1988; Goldberg et al., 1991; Heidemann et al., 1991). However, observations described here emphasize the importance of attachment of the distal ends of filopodia to the substrate whereas models of growth cones depict more extensive interactions with the substrate. Although the latter models may be more pertinent to growth on homogeneous substrates, the present models could be applicable to the navigation of growth cones in more complex environments. For example, studies of grasshopper neurons developing in vivo have shown that the direction of growing axons sometimes is determined by a single filopodium that contacts a guide post cell and then is invaded by cytoplasm (O'Connor et al., 1990; Sabry et al., 1991).

A prediction of both models presented here is that actin filaments in filopodia undergo retrograde movement prior to the beginning of neurite formation but that this movement stops when the tips of filopodia become anchored to a substrate. Techniques have recently been developed that make it possible to visualize actin filaments directly in living cells, and these techniques have confirmed that actin filaments in lamellipodia of growth cones and fibroblasts move retrogradely under some circumstances (Wang, 1985; Okabe and Hirokawa, 1991; Theriot and Mitchison, 1991, 1992). Application of these techniques to model systems like those described here should show whether the dynamics of actin filaments are modulated by interactions with the growth substrate.

\section{References}

Abercrombie M, Heaysman JEM, Pegrum SM (1970) The locomotion of fibroblasis in culture. III. Movements of particles on the dorsal surface of the leading lamella. Exp Cell Res 62:389-398.

Aletta JM, Greene LA (1988) Growth cone configuration and advance: a time-lapse study using video-enhanced differential interference contrast microscopy. J Neurosci 8:1425-1435.

Allen RD, Stromgren Allen N, Travis JL (1981) Video-enhanced contrast, differential interference contrast (AVEC-DIC) microscopy: a new method capable of analyzing microtubule-related motility in the reticulopodial network of Allogromia latticollaris. Cell Motil Cytoskel 1:291-302.

Baron-Van Evercooren A, Kleinman HK, Ohno S, Marangos P, Schwartz
JP, Dubois MF (1982) Nerve growth factor, laminin, and fibronectin promote neurite growth in human fetal sensory ganglia cultures. J Neurosci Res 8:179-193.

Bass PW, Ahmad FJ (1992) The plus ends of stable microtubules are the exclusive nucleating structures for microtubules in the axon. J Cell Biol 116:1231-1241.

Bray D (1970) Surface movements during the growth of single explanted neurons. Proc Natl Acad Sci USA 65:905-910.

Bray D (1973) Branching patterns of individual sympathetic neurons in culture. J Cell Biol 56:702-712.

Bray D (1979) Mechanical tension produced by nerve cells in tissue culture J Cell Sci 37:391-410.

Bray D (1984) Axonal growth in response to experimentally applied tension. Dev Biol 102:379-389.

Bray D, Chapman K (1985) Analysis of microspike movements on the neuronal growth cone. J Neurosci 12:3204-3213.

Bridgman PC, Dailey ME (1989) The organization of myosin and actin in rapid frozen nerve growth cones. J Cell Biol 108:95-109.

Bruckenstein DA, Higgins D (1988) Morphological differentiation of embryonic rat sympathetic neurons in tissue culture: I. Conditions under which neurons form axons but not dendrites. Dev Biol 128: 324-336.

Burton PR, Paige JL (1981) Polarity of axoplasmic microtubules in the olfactory nerve of the frog. Proc Natl Acad Sci USA 78:32693273.

Buxbaum RE, Heidemann SR (1988) A thermodynamic model for force integration and microtubule assembly during axonal elongation. J Theor Biol 134:379-390.

Cambray-Deakin M $\Lambda$, Morgan $\Lambda$, Burgoyne RD (1987) Sequential appearance of cytoskeletal components during the early stages of neurite outgrowth from cerebellar granule cells in vitro. Dev Brain Res 37:197-207.

Collins F (1978a) Axon initiation by ciliary neurons in culture. Dev Biol 65:50-57.

Collins F (1978b) Induction of neurite outgrowth by a conditionedmedium factor bound to the culture substratum. Proc Natl Acad Sci USA 75:5210-5213.

Curtis ASG (1964) The mechanism of adhesion of cells to glass: a study by interference reflection microscopy. J Cell Biol 20:195-215.

Dotti CG, Banker G (1992) Intracellular organization of hippocampal neurons during the development of neuronal polarity. J Cell Sci [Suppl] 15:75-84.

Dotti CG, Sullivan CA, Baker GA (1988) The establishment of polarity by hippocampal neurons in culture. J Neurosci 8:1454-1468.

Drazba J, Smith CL, Lemmon V (1992) Patterns of growth cone contact with different adhesive substrates as determined by interference reflection microscopy. Soc Neurosci Abstr 18:1460.

Edgar D, Timpl R, Thoenen H (1984) The heparin-binding domain of laminin is responsible for its effects on neurite outgrowth and neuronal survival. EMBO J 3:1463-1468.

Falconer MM, Vielkind U, Brown DL (1989) Establishment of a stable, acetylated microtubule bundle during neuronal commitment. Cell Motil Cytoskel 12:169-180.

Fisher GW, Conrad PA, DeBiasio RL, Lansing Taylor D (1988) Centripetal transport of cytoplasm, actin, and the cell surface in lamellipodia of fibroblasts. Cell Motil Cytoskel 11:235-247.

Forscher P, Smith SJ (1988) Actions of cytochalasins on the organization of actin filaments and microtubules in a neuronal growth cone. $J$ Cell Biol 107:1505-1516.

Forscher P, Smith SJ (1990) Cytoplasmic actin filaments move particles on the surface of a neuronal growth cone. In: Optical microscopy for biology (Herman B, Jacobson K, eds), pp 459-471. New York: Wiley-Liss.

Forscher P, Lin CH, Thompson C (1992) Novel form of growth cone motility involving site directed actin filament assembly. Nature 357: $515-518$

Goldberg DJ, Burmeister DW (1986) Stages in axon formation: observations of growth of Aplysia axons in culture using video-enhanced contrast-differential interference contrast microscopy. J Cell Biol 103: 1921-1931.

Goldberg DJ, Burmeister DW, Rivas RJ (1991) Video microscopic analysis of events in the growth cone underlying axon growth and the regulation of these events by substrate-bound proteins. In: The nerve growth cone (Letourneau PC, Kater SB, Macagno ER, eds), pp 79 96. New York: Raven. 
Gundersen RW (1988) Interference reflection microscopic study of dorsal root growth cones on different substrates: assessment of growth cone-substrate contacts. J Neurosci Res 21:298-306.

Harrison RG (1914) The reaction of embryonic cells to solid structure. J Exp Zool 7:521-544.

Heidemann SR, Landers JM, Hamborg MA (1981) Polarity orientation of axonal microtubules. J Cell Biol 91:661-665.

Heidemann SR, Lamoureaux P, Buxbaum RE (1990) Growth cone behavior and production of traction force. J Cell Biol 111:1940-1957.

Heidemann SR, Lamoureaux P, Buxbaum RE (1991) On the cytomechanics and fluid dynamics of growth cone motility. J Cell Sci [Suppl] 15:35-44.

Izzard CS, Lochner L (1976) Cell-to-substrate contacts in living fibroblasts: an interference reflexion study with an evaluation of the technique. J Cell Sci 21:129-159.

Jacobs JR, Stevens JK (1986) Changes in the organization of the neuritic cytoskeleton during nerve growth factor activated differentiation of PC12 cells: a serial electron microscopic study of the development and control of neurite shape. J Cell Biol 103:895-906.

Jacobs JR, Stevens JK (1987) Dynamics of behaviour during neuronal morphogenesis in culture. Cell Motil Cytoskel 8:250-260.

Jacobson M (1978) Developmental neurobiology. New York: Plenum.

Jacobson M. Huang S (1985) Neurite outgrowth traced by means of horseradish peroxidase inherited from neuronal ancestral cells in frog embryos. Dev Biol 110:102-113.

Kucik DF, Kuo SC, Elson EL, Sheetz MP (1991) Preferential attachment of membrane glycoproteins to the cytoskeleton at the leading edge of lamella. J Cell Biol 1 14:1029-1036.

Lefcort F, Bentley D (1989) Organization of cytoskeletal elements and organelles preceding growth cone emergence from an identified neuron in situ. J Cell Biol 108:1737-1749.

Letourneau PC (1975) Possible roles for cell-to-substratum adhesion in neuronal morphogenesis. Dev Biol 44:77-91.

Letourneau PC (1982) Nerve fiber growth and its regulation by extrinsic factors. In: Neuronal development (Spitzer NC, ed), pp 213 254. New York: Plenum.

Letourneau PC, Kater SB, Macagno ER (1991) The nerve growth cone. New York: Raven.

Lim S-S, Sammak PJ, Borisy GG (1989) Progressive and spatially differentiated stability of microtubules in developing neuronal cells. J Cell Biol 109:253-263.

Luckenbill-Edds L, Van Horn C, Greene LA (1979) Fine structure of initial outgrowth of processes induced in pheochromocytoma cell line (PC12) by nerve growth factor. J Neurocytol 8:493-511.

Manthorpe M. Engvall E, Ruoslahti E, Longo FM, Davis GE, Varon S (1983) Laminin promotes neuritic regeneration from cultured peripheral and central neurons. J Cell Biol 97:1882-1890.

Marusich MF, Pourmehr K, Weston JA (1986) The development of an identified subpopulation of avian sensory neurons is regulated by interaction with the periphery. Dev Biol 118:505-510.

Mitchison T, Kirschner M (1988) Cytoskeletal dynamics and nerve growth. Neuron 1:761-772.

Nakai J, Kawasaki Y (1959) Studies of the mechanism determining the course of nerve fibers in tissue culture: 1 . The reaction of the growth cone to various obstructions. Z Zellforsch 51:108-122.

Nowakowski RS, Rakic P (1979) The mode of migration of neurons to the hippocampus: a Colgi and electron microscopic analysis in foetal rhesus monkey. J Neurocytol 8:697-718.

O'Connor T, Duerr J, Bentley D (1990) Pioneer growth cone steering decisions mediated by single filopodial contacts in situ. J Neurosci 10:3935-3946.

Okabe S, Hirokawa $N$ (1991) Actin dynamics in growth cones. J Neurosci 11:1918-1929.

Piperno GM, Ledizet M, Chang X (1987) Microtubules containing acetylated alpha-tubulin in mammalian cells in culture. J Cell Biol 104:289-302.
Platt JI, Michael AF (1983) Retardation of fading and enhancement of intensity of immunofluorescence by $p$-phenylenediamine. J Histol Cytol 31:840-842.

Ramon y Cajal S (1911) Histologie du systeme nerveux de l'homme et des vertébrés (Asoulay L, trans). Reprint, Madrid: Instituto Ramon y Cajal del C.S.I.C, 1952.

Reinsch SS, Mitchison T, Kirschner M (1991) Microtubule polymer assembly and transport during axonal elongation. J Cell Biol 115 365-379

Robson SJ, Burgoyne RD (1989) Differential localization of tyrosinated, detyrosinated, and acetylated alpha-tubulin in neurites and growth cones of dorsal root ganglion neurons. Cell Motil Cytoskel 12: $273-282$.

Rohrer H, Thoenen H (1987) Relationship between differentiation and terminal mitosis: chick sensory and ciliary neurons differentiate after terminal mitosis of precursor cells, whereas sympathetic neurons continue to divide after differentiation. J Neurosci 7:3739-3748.

Sabry JH, O'Connor TP, Evans L, Toroian-Raymond A, Kirschner M Bentley D (1991) Microtubule behavior during guidance of pioneer neuron growth cones in situ. J Cell Biol 115:381-395.

Schliwa M, van Blerkom J (1981) Structural interaction of cytoskeletal components. J Cell Biol 90:222-235.

Schulze E, Kirschner M (1987) Dynamic and stable populations of microtubules in cells. J Cell Biol 104:277-288

Shaw G (1991) Neurofilament proteins. In: The neuronal cytoskeleton (Burgoyne RD, ed), pp 185-214. New York: Wiley-Liss

Sheetz MP, Turney S, Qian H, Elson EL (1989) Nanometre-level analysis demonstrates that lipid flow does not drive membrane glycoprotein movements. Nature 340:284-288

Sheetz MP, Baumrind NL, Wayne DB, Pearlman AL (1990) Concentration of membrane antigens by forward transport and trapping in neuronal growth cones. Cell 61:231-241.

Sheetz MP, Wayne DB, Pearlman AL (1992) Extension of filopodia by motor-dependent actin assembly. Cell Motil Cytoskel 22:160-169.

Smith CL (1992) Entry of microtubules into developing neurites does not require polymerization of tubulin. Soc Neurosci Abstr 18:1286.

Smith CL, Munro EM (1990) Axon initiation and the establishment of polarity by neurons grown in vitro. Soc Neurosci Abstr 16:812.

Smith SJ (1988) Neuronal cytomechanics: the actin based motility of growth cones. Science 242:708-715.

Soloman F (1979) Detailed neurite morphologies of sister neuroblastoma cells are related. Cell 16:165-169.

Theriot JA, Mitchison TJ (1991) Actin microfilament dynamics in locomoting cells. Nature 352:126-131.

Theriot JA, Mitchison TJ (1992) Comparison of actin and cell surface dynamics in motile fibroblasts. J Cell Biol 118:367 377

Tosney KW, Wessells NK (1983) Neuronal motility: the ultrastructure of veils and microspikes correlates with their motile activities. J Cell Sci 61:389-411.

Wang Y-L (1985) Exchange of actin subunits at the leading edge of living fibroblasts: possible role of treadmilling. J Cell Biol 101:597602 .

Wehland J, Willingham MC, Sandoval IV (1983) A rat monoclonal antibody reacting specifically with the tyrosylated form of alpha-tubulin. I. Biochemical characterization, effects on microtubule polymerization in vitro, and microtubule polymerization and organization in vivo. J Cell Biol 976:1467-1475

Wessells NK, Johnson SR, Nuttall RP (1978) Axon initiation and growth cone regeneration in cultured motor neurons. Exp Cell Res $117: 335.345$.

Zheng JP, Lamoureaux P, Santiago V, Dennerll T, Buxbaum RE, Heidemann SR (1991) Tensile regulation of axonal elongation and iniliation. J Neurosci 11:1117-1125. 